\title{
PATRICIA STROHMAIER*
}

\section{GESCHNITZT, GESTICKT, GEMALT WIRKSTRATEGIEN SPÄTMITTELALTERLICHER ANDACHTSBILDER ${ }^{1}$}

Carved, embroidered, painted. Effectual strategies of late medieval devotional images. Based on the assumption that the late medieval tension between the desire for God's grace (Heilssehnsucht) and the uncertainty of it (Heilsunsicherheit) influenced devotional art, the article focuses on three late medieval images designed for private devotional use. A prayer nut carved from boxwood, a triptych embroidered with silk, gold and silver, and the Leipzig Man of Sorrows by the so-called Master Francke all show a popular image of the late Middle Ages, the Man of Sorrows surrounded by the instruments of the Passion. They all make use of techniques to create both closeness and distance to what they represent. The images pull the beholder close through a multitude of details, a realistic style and the illusion of the Man of Sorrows being palpably present, to the point of triggering an impulse to touch him. At the same time, they fail to provide the closeness they suggest. The border between the beholder's sphere and that of the Christ represented, marked by the necessity to open the objects first, cannot be crossed. Blurred details, overlappings and the impossibility to touch the fine artworks, lest they be impaired, push the beholder away, leaving the contemplation of the presented image to his or her inner eye instead. This fine balance designed to induce devotion gets lost in the modern era when the images' skilfulness becomes the main motive for admiration.

Keywords: devotional images, late medieval piety, prayer nuts, embroidery, early German painting

I.

In dem Hymnenzyklus Ad singula membra Christi patientis des Arnulf von Löwen (1200-1250) richtet die Sprechinstanz Verse an ein imaginiertes Bild des Gekreuzigten: „So als ob du gegenwärtig wärest, trete ich an dich heran, ja, ich glaube vielmehr, dass du gegenwärtig bist, o wie nackt sehe ich dich hier."2 Sie stellt sich alle Einzelheiten des geschundenen Leibs Christi vor, um sich mit seinem Leiden zu verbinden: „Deine roten Wunden und deine tiefen Male lass in mein Herz einschreiben, auf dass ich ganz an dich geheftet werde. "ㄱ In diesen Versen wird - auch durch die direkte Ansprache - der Gekreuzigte vor dem inneren Auge präsent, wodurch eine Nähe zu Chris-

\footnotetext{
* Patricia Strohmaier, wissenschaftliche Mitarbeiterin, Heinrich-Heine-Universität Düsseldorf, Institut für Kunstgeschichte; E-Mail: patricia.strohmaier@uni-duesseldorf.de
}

tus entsteht. Die Spuren der Passion werden kommemoriert, indem die Sprechinstanz den Gliedmaßen Christi je eigene Verse widmet. Entstanden in der ersten Hälfte des 13. Jahrhunderts, taucht der Text unter anderem in einem Gebetbuch aus dem AugustinerChorfrauenstift Heiningen von 1410 auf und bezeugt damit die anhaltende Beliebtheit des Hymnenzyklus. ${ }^{4}$ Ewas allgemeiner heißt es im Prolog der Meditationes Vitae Christi (Mitte 14. Jahrhundert) des Johannes de Caulibus, neben der Imitatio Christi von Thomas à Kempis (1380-1471) und der Vita Christi des Ludolphus de Saxonia (1300-1377/1378), eines der bekanntesten spätmittelalterlichen Andachtsbücher: „Wenn Du aber recht viel Frucht aus der Betrachtung schöpfen willst, dann musst Du Dir alles, was der Herr Jesus redet oder tut, so lebhaft vergegenwärtigen, als hörest Du es mit eigenen Ohren und sähest es mit eigenen Augen, dann muss dein ganzes Herz dabei sein voll freudiger und gespannter Aufmerksamkeit; dann musst du alle Zerstreuungen und Erdensorgen 
verbannen." ${ }^{5}$ Die Geisteshaltung, die in beiden Textstellen zum Ausdruck kommt, fasst Berndt Hamm folgendermaßen zusammen: „Wer nach den innovativen Zügen der spätmittelalterlichen Religiosität [...] fragt, stößt vor allem auf Phänomene einer intensivierten Vergegenwärtigung des Heiligen, Heilenden und Heilvollen, die man unter dem Leitbegriff der ,nahen Gnade' zusammenfassen kann; sie reagierten offensichtlich auf ebenfalls intensivierte Vorstellungen von der bedrängenden Nähe satanischer Mächte und göttlicher Strafen, also einer ,nahen Ungnade،."6 Dies hat nach Hamm die Entwicklung von Medien zur Folge, die einen Zugang zur göttlichen Gnade, die durch die Opferung des Gottessohnes gewährt worden ist, ermöglichen. Er unterteilt diese Medien in drei Kategorien: das Erlösungswerk Christi als Medialität erster Ordnung; eine Partizipationsmedialität, z.B. in Form von Gebeten und Kommunion, die auf Meditation abzielt - hierzu würden die oben zitierten Schriften zählen; schließlich die Hilfsmedialität, die über das im Mittelalter als körperlicher Vorgang begriffene Sehen funktioniert und eine mühelose Form des Gnadenerwerbs darstellt. Letztere ist auf „Körperlichkeit, Materialität und sinnliche Wahrnehmbarkeit ${ }^{\text {" }}$ ausgerichtet und erleichtert so der oder dem Gläubigen, Zugang zum Heil zu finden. ${ }^{8}$ Dazu zählt Hamm z.B. Kopien von Gnadenbildern, die eine beschwerliche Pilgerreise ersetzen. Allerdings sind die drei Kategorien nicht scharf voneinander zu trennen. Hamm zeigt, wie alle drei Formen der Medialität auf einem Einblattholzschnitt zusammentreffen: Die Darstellung von Christus am Kreuz zwischen den Schächern und seiner von einem Schwert durchbohrten Mutter, die von Johannes gestützt wird, veranschaulicht das Erlösungswerk Christi als Medialität erster Ordnung. Das begleitende Gebet und das daran anschließende Ablassversprechen stellen die Partizipationsmedialität dar. Das gedruckte Blatt selbst, mit Bild und Anleitung, günstig zu erwerben und überall zu gebrauchen, repräsentiert die Hilfsmedialität. ${ }^{9}$ Ein besonders eindrückliches Beispiel dafür bietet der so genannte Mirakelmann aus der Nikolaikirche in Döbeln, ein lebensgroßer Kruzifixus mit beweglichen Armen und Beinen, Kopf- und Barthaaren aus Tierhaar und einem Behälter für Flüssigkeit im Inneren. Dieser ermöglichte, dass aus der Seitenwunde der Christusfigur Blut und Wasser liefen, sobald hineingestochen wurde. ${ }^{10}$ Bei diesem Bildwerk benötigte die oder der Betrachtende nicht mehr viel Vorstellungskraft, um sich den Gottessohn und seine Passion zu vergegenwärtigen.
Die Medien der nahen Gnade bezeugen gleichzeitig, wie bereits zitiert, die Angst vor dem Gegenteil, der Ungnade. Daraus resultiert ein Spannungsfeld zwischen Vergegenwärtigung/Nähe des Heils und einer möglichen Entziehung/Ferne des Heils. Das Heilsbedürfnis wird von einer Heilsungewissheit angetrieben - sichtbar z.B. in der Ablasspraxis, denn niemand wusste genau, wie viel Zeit im Fegefeuer verbüßt werden musste. So schreibt Thomas à Kempis in seiner Imitatio Christi, die auch verschiedene Heilsmedien wie Gebet und Kommunion thematisiert: „Versprich dir in diesem Leben niemals Sicherheit, auch wenn du als guter Mönch oder frommer Einsiedler angesehen wirst." 11 Der im Kapitel, das zu Einsamkeit und Stille auffordert, etwas lapidar wirkende Satz unterstreicht, dass zwar alle Bemühungen zum Gnadenerwerb unternommen werden müssen, die Heilsungewissheit aber im irdischen Leben fortbesteht.

Dieses Spannungsverhältnis scheint ein der spätmittelalterlichen Religiosität zugrunde liegender Zug zu sein. So ist es konsequent, die Kunst im Dienste der Frömmigkeit, speziell Andachtsbilder, auf ihre Positionierung innerhalb dieser Dichotomie zu bestimmen. Im Folgenden sollen die Wirkstrategien von drei für den privaten Gebrauch bestimmten Bildwerken - einer Mikroschnitzerei, einer Reliefstickerei und einer Tafelmalerei - vor diesem Hintergrund untersucht werden. Sie bewegen sich, so die These, zwischen den beschriebenen Polen Vergegenwärtigung/Nähe und Entziehung/Distanz. Diese Wirkung ist dabei nicht von einer bestimmten Gattung oder speziellen Materialien abhängig, sondern konnte in potenziell jeder Gattung erzielt werden. ${ }^{12}$ Zur besseren Veranschaulichung wurden die drei Objekte nach ihrem gemeinsamen Motiv ausgewählt, dem Schmerzensmann. Er ist als mehrschichtig angelegtes „Allwesenheitsbild“13 eine der wichtigsten und beliebtesten Christusdarstellungen des Spätmittelalters und entspricht dem Bedürfnis, durch die Betrachtung der Leiden Christi zu einem gottgefälligen Lebenswandel zu finden. ${ }^{14} \mathrm{Da}$ die Andachtsbilder der Erzeugung der richtigen inneren Bilder dienten, ${ }^{15}$ ist ihnen eine Strategie zu Eigen, die dieses Erzeugen innerer Bilder unterstützte und somit zur Überwindung der in den Bildern gleichzeitig angelegten Distanz beitrug. Diese Strategie kann je nach Medium anders aussehen: bewusste Monochromie als Aufforderung, die Bilder mit dem geistigen Auge auszumalen; Überschneidungen, die Lücken entstehen lassen, welche durch die betrachtende Person geschlossen werden müssen; Unschärfen, die das innere Auge scharfstellt. Die Entwicklung von 
Andachtsbildern und Schmerzensmanndarstellungen ist an anderen Stellen diskutiert worden und wird hier nicht wiederholt. ${ }^{16}$ Stattdessen steht die Untersuchung und Deutung der drei Objekte im Vordergrund.

II.

Im Besitz des Hamburger Museums für Kunst und Gewerbe befindet sich eine so genannte Betnuss (Abb. 1). ${ }^{17}$ Es handelt sich dabei um zwei halbkugelförmige Sphären aus Buchsbaum, die über das Scharnier eines Messinggehäuses miteinander verbunden sind und durch Schließen eine kleine Kugel bilden. Am Gehäuse befindet sich eine Öse, die darauf hindeutet, dass der Gegenstand an einer Kette getragen werden konnte. In den beiden Sphären sind zwei Miniaturschnitzereien, links eine figurenreiche Kreuzigung und rechts die Gregorsmesse. Die Schnitzereien sind mit den Sphären verbunden, demnach aus einem Stück gearbeitet.

Das Gehäuse zeigt eine Gravur mit dem Opfer Abrahams sowie Pyramos und Thisbe. Seine gleichzeitige Entstehung mit dem Inneren ist eher unwahrscheinlich, da die Gruppe der Betnüsse ${ }^{18}$ mehrheitlich mit gotischem Maßwerk verzierte Gehäuse aus
Buchsbaum aufweist. Zudem zeigen die Vergleichsbeispiele, dass die Szenen in der Regel übereinander, nicht nebeneinander angeordnet waren. Aufgrund der inzwischen stark angewachsenen Literatur zu Betnüssen bzw. Mikroschnitzereien aus Buchsbaum können hier nur einige Fakten zusammengefasst werden. ${ }^{19}$ Entstanden sind diese Objekte in einem relativ kurzen Zeitraum zwischen 1500 und 1530. Als Herstellungsort wird eine Werkstatt in den Niederlanden, in der Provinz Holland, vermutet. ${ }^{20}$ Die Hamburger Betnuss ordnet sich in diese Werkgruppe ein und kann daher auch als Produkt dieser Werkstatt angesehen werden. Neben Betnüssen wurden dort noch weitere Miniaturschnitzereien aus Buchsbaum gefertigt, z.B. kleine Altarretabel, Memento-Mori-Anhänger und sogar Buchstaben. ${ }^{21}$ Alle Produkte gehören in den Bereich der Andachtspreziosen. Sie waren aufgrund ihrer aufwendigen Fertigung - die geschnitzten Gegenstände und Figuren bewegen sich im Millimeterbereich teure Instrumente für die Andacht, gleichzeitig auch für die öffentliche Zurschaustellung frommer Haltung und sozialen Prestiges. Für einzelne Gegenstände lassen sich aufgrund angebrachter Familienwappen oder gesicherter Provenienz hochrangige Stifter bis in die europäischen Herrscherhäuser nachweisen. Betnüsse - das bezeugen überlieferte Exemplare und gemalte

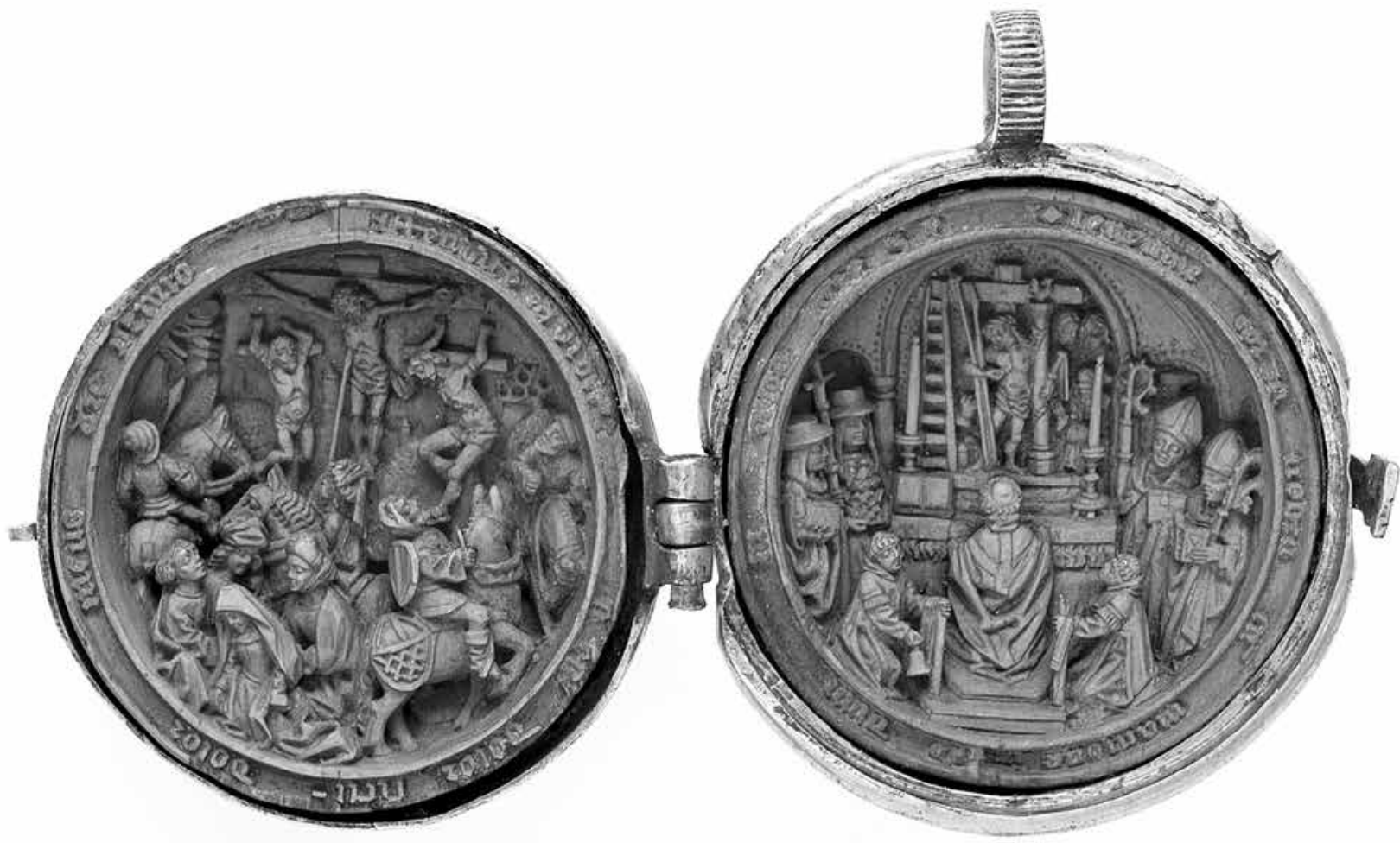

Abb. 1. Sog. Werkstatt des Adam Dircksz: Betnuss mit Kreuzigung und Gregorsmesse, 1500-1530, Dm. 4,1 cm. Hamburg, Museum für Kunst und Gewerbe, Inv.-Nr. 1878.134 (Foto: Museum für Kunst und Gewerbe, Hamburg, Maria Thrun) 
Bildwerke - wurden auch an einem Rosenkranz getragen und bildeten dort die Pater-Noster-Kugel nach zehn kleineren Ave-Maria-Perlen. ${ }^{22}$ Sie waren dadurch unmittelbar in eine verbreitete spätmittelalterliche Frömmigkeitspraxis eingebunden. Obgleich Bestandteil der Marienverehrung, war das Rosenkranzgebet eng mit der Passionsfrömmigkeit verbunden, denn die aneinandergereihten Mariengrüße leiteten zum Christuslob über. ${ }^{23}$ Das Gebet nach einer Zählschnur erleichterte die Konzentration, war aufgrund des taktilen Reizes zugleich materielle Versicherung ${ }^{24}$ und ermöglichte dem Betenden eine Registrierung von „frommen Verdiensten“. 25 Während aber die einfacheren Perlen ein routiniertes Herunterbeten begünstigten, lud die dazwischen geschaltete, äußerst fein gearbeitete Betnuss zu einem längeren Verweilen ein.

Doch zurück zur Hamburger Betnuss: Auf wenigen Zentimetern erstreckt sich links eine Kreuzigungsszene (Abb. 1), deren Detail- und Figurenreichtum den großen südniederländischen Schnitzretabeln ähnelt. ${ }^{26}$ Die obere Hälfte des Bildes nimmt der gekreuzigte Christus ein, links und rechts der gute und der böse Schächer. Im Hintergrund ist mit einiger Mühe die Stadt Jerusalem mit Türmen zu erkennen. Am linken Rand befindet sich eine Felsformation, die vielleicht auf das Grab Christi vorausweist und so eine imaginative Fortsetzung der Szene zulässt. Unterhalb der Gekreuzigten befinden sich vier Männer auf Pferden, deren Position auf Abwechslung angelegt ist. Links sind Pferd und Reiter von hinten zu sehen, ganz rechts von vorne. Die beiden Reiter in der Mitte sind von der Seite dargestellt, wobei das Pferd des rechten Reiters seinen Kopf nach hinten wendet und das Pferd des linken Reiters gänzlich im Profil wiedergegeben ist. Auch die Kleidung variiert. Der Reiter ganz links trägt Rüstung und Helm, der in der Mitte rechts ein kurzes Obergewand, eine Gugel und ein Schild. Der Reiter in der Mitte links trägt einen Turban oder eine wie ein Turban gewickelte Gugel. Dieser Reiter ist als Longinus zu erkennen, da er mit einer Lanze die Seite Christi offnet. Er steht direkt unter Christus und ist damit von den vier Reitern hervorgehoben. Vor Longinus, am Bildrand leicht rechts, repräsentiert eine Gruppe von vier Figuren Maria und Johannes in Begleitung von zwei Personen. Während Johannes bewegt zu Christus am Kreuz blickt, ist die mit einem langen Schleier angetane Maria ohnmächtig zusammengesunken, sodass sie gestützt werden muss. Ihr nach links gesunkener Kopf parallelisiert die Kopfhaltung ihres Sohnes am Kreuz und verdeutlicht ihre für die Andacht vorbildhafte compassio. ${ }^{27}$ Die
Frau rechts hinter Maria trägt eine Haube, die Person links bedeckt ihr offenes Haar mit einer nicht näher zu definierenden Kopfbedeckung und greift sich als Zeichen der Trauer ins Gesicht. Allein die Beschreibung dieser sich nur auf $4 \mathrm{~cm}$ abspielenden Szene verdeutlicht, wie viele Figuren und Details ausgearbeitet wurden. Manche Motive sind nur angedeutet, wie die Stadt Jerusalem im Hintergrund, andere weisen einen erstaunlichen Detailreichtum auf, wie die netzartige Decke auf dem Pferd des Reiters in der Mitte rechts.

Bevor dieser Befund weiterverfolgt wird, schließt sich die Beschreibung der Gregorsmesse an. Auch dieser Bildtypus ist Gegenstand zahlreicher Untersuchungen, weshalb seine Entwicklung und Bedeutung hier nicht wiedergegeben werden.. ${ }^{28}$ An dieser Stelle soll eine kurze Zusammenfassung genügen: Die Gregorsmesse gilt aktuell als Bild, das eine Vision Papst Gregors des Großen während der Messe festhält. Ihm erschien darin Christus als Schmerzensmann. Davon ließ Gregor ein Bild anfertigen und verband es mit einem Ablass. Als dieses Bild nach der Vision gilt eine Mosaikikone in Santa Croce in Gerusalemme. ${ }^{29}$ Die Ikone kam nicht vor Ende des 14. Jahrhunderts nach Rom. Die Legende um die Vision Gregors bildete sich heraus, um der Ikone eine sakrale Aura zu verleihen. Wie erfolgreich diese Legende war, zeigen die zahlreichen Darstellungen der Gregorsmesse in der spätmittelalterlichen Kunst. ${ }^{30}$

In einem angedeuteten Kirchengewölbe steht Christus als Schmerzensmann vor seinem Kreuz hinter dem Altar auf einer Art Predella (Abb. 1). Sein linker Arm umgreift die Geißelsäule, auf der der Hahn als Symbol der Leugnung Christi durch Petrus steht. In der linken Hand hält er eine Geißel. Sein rechter Arm umfasst die Lanze und den Stab mit dem Essigschwamm, deren Enden vor dem rechten Fuß verankert sind. Mit der rechten Hand weist er auf seine Seitenwunde. Neben der Dornenkrone auf seinem Kopf sind noch weitere arma Christi abgebildet, darunter die Leiter, schlagende Hände und mehrere Köpfe. Auf dem Altar sind zwei große Kerzen aufgestellt und liegt ein aufgeschlagenes Buch. Vor dem Altar, auf den Altarstufen, kniet der mit einer Kasel bekleidete Gregor als Rückenfigur, assistiert von - der Kleidung nach zu urteilen - Diakon und Subdiakon links und rechts. Die linke Person hält eine Glocke in den Händen, die typischerweise bei der Elevation der Hostie geläutet wurde. Die Stäbe in den Händen der beiden Assistenten sind abgebrochen. Links und rechts vom Altar steht jeweils eine Zweiergruppe. Links handelt es sich um Kardinäle, wie an der Kopfbedeckung zu erken- 
nen ist. Der hintere Kardinal hält die Tiara des Papstes, der vordere einen Kreuzstab und ein Buch. Rechts stehen zwei Bischöfe, erkennbar an den Mitren und den Bischofsstäben, die beide mitführen. Sie halten jeweils ein Buch in den Händen, wobei der vordere Bischof das Buch aufgeschlagen vor sich hält. Über dem Kopf des hinteren Bischofs wird unter dem Gewölbebogen ein Gegenstand sichtbar, der einem Hammer ähnelt und somit ein weiteres Passionswerkzeug darstellen könnte. Auch diese Szene überrascht durch ihr Interesse am Detail. So befinden sich z.B. vorne an der Altarmensa Fransen, die wohl zu einem Fürleger gehören, und an dem Kerzenständer rechts auf der Mensa ist zu erkennen, dass er auf kleinen Füßen steht. Eine wiederholte Betrachtung führt hier zur Aufdeckung immer neuer Details.

Beide Szenen sind von einer Inschrift umgeben. Der Kreuzigungsszene ist folgender Satz beigegeben: „Schaut doch und seht, ob irgendein Schmerz ist wie mein Schmerz."31 Der alttestamentliche Vers begleitete nicht nur die Darstellung des Lanzenstoßes durch Longinus in der Biblia Pauperum. ${ }^{32}$ Er forderte den Einzelnen zum Nachvollzug der Leiden Christi auf, gemäß der Vita Christi des Ludolphus de Saxonia, in der er die meditative Betrachtung des Gekreuzigten mit diesem Satz empfahl. ${ }^{33}$ Dazu passt auch Thomas à Kempis' Imitatio Christi, in der er in einem eigenen Kapitel über die Kreuznachfolge schrieb und von der oder dem Lesenden verlangte, in Anbetracht der noch viel größeren Leiden Christi selbst zum Leiden bereit zu sein. ${ }^{34}$ Darüber hinaus war der Vers Bestandteil der Liturgie der Karwoche und stellte somit für den Lateinkundigen eine Verbindung mit der Erinnerung an das Opfer Christi in der Messe her. ${ }^{35}$ Die vor dem Kreuz stehende und der Ohnmacht nahe Muttergottes gibt dem oder der Andächtigen ein zu verfolgendes Beispiel für compassio vor, denn sie trauert nicht nur, sondern erfährt die Leiden ihres Sohnes auch körperlich. Spätmittelalterliche Marienklagen schildern, dass Maria die Öffnung der Seite Christi durch Longinus wie ein Schwert durchfahren habe. ${ }^{36}$

Die Gregorsmesse wird von der ebenfalls aus den Klageliedern stammenden Inschrift „Lasst uns unser Herz samt den Händen aufheben zu Gott im Himmel" umrundet. ${ }^{37}$ Beide Inschriften erscheinen häufig auf den niederländischen Buchsbaumschnitzereien, nicht immer in Verbindung mit denselben Szenen. In einer Betnuss im British Museum (London) sind beide Bibelzitate auf der Hülle eingeschnitzt, während Kreuzigung und Kreuztragung im Inneren von anderen Zitaten begleitet werden. ${ }^{38}$ Im Metropolitan Museum

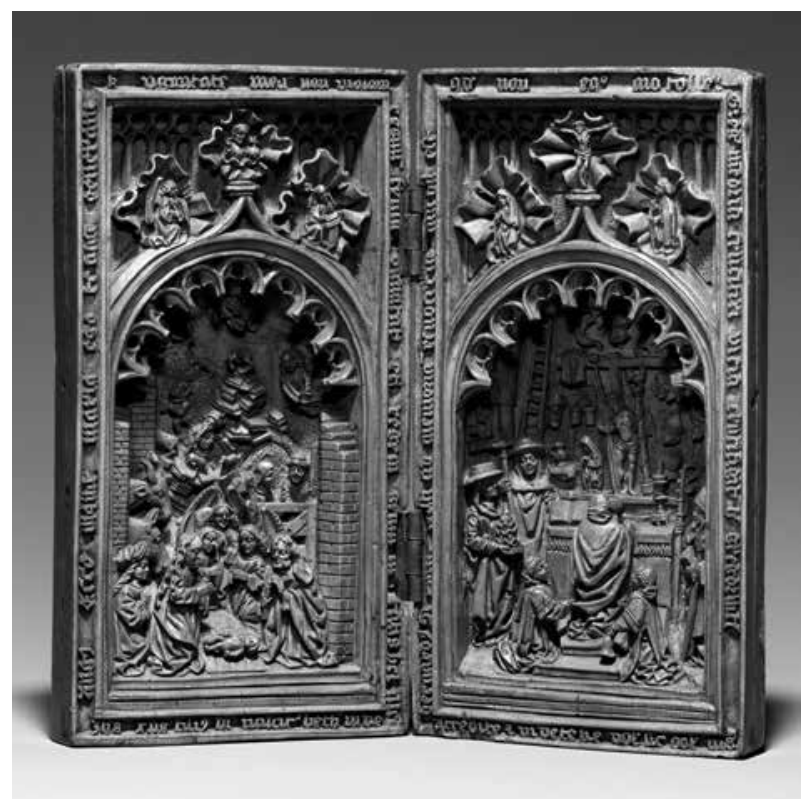

Abb. 2. Sog. Werkstatt des Adam Dircksz: Diptychon mit Geburt Christi und Gregorsmesse, 1500-1530,

$8,3 \times 4,5 \mathrm{~cm}$ (geschlossen). New York, Metropolitan Museum of Art, Inv.-Nr. 17.190.476

(Foto: The Metropolitan Museum of Art, New York)

of Art (New York) erscheinen beide Verse ebenfalls auf den Außenseiten zweier Betnüsse: eine mit Kreuzigung und Anbetung der heiligen drei Könige, die andere mit Kreuzigung und Christus vor Pilatus. ${ }^{39}$ Hier bereiten die außen angebrachten Inschriften der noch geschlossenen Betnüsse auf die Bilder im Inneren vor, indem sie eine andächtige Haltung erzeugen. Auf einem in derselben Werkstatt entstandenen Diptychon im Metropolitan Museum of Art, das Geburt Christi und Gregorsmesse kontrastiert, befinden sich auf dem Rahmen der Gregorsmesse insgesamt vier Inschriften (Abb. 2)..$^{40}$ Jene am unteren Bildrand entspricht derjenigen der Kreuzigungsszene in der Hamburger Betnuss. Auf dem Rahmen rechts, links und oben werden Aussprüche Bernhards von Clairvaux und Gregors zitiert. Die Sprüche können das Verständnis der Gregorsmesse in der Hamburger Betnuss erweitern. Sie betonen beide die heilbringende Wirkung der Leiden Christi. Wer sich diese vor Augen führt, ist einerseits vor der Sünde gefeit und wird andererseits die Beschwerlichkeiten seines eigenen Lebens bereitwilliger ertragen. ${ }^{41}$ Die oder der Betrachtende hebt Herz und Hände der Aufforderung in der Gregorsmesse der Hamburger Betnuss folgend gen Himmel, richtet seinen Geist also auf den Gegenstand seiner Andacht. Gregor ist hierbei als Beispiel richtiger Betrachtung gegeben. ${ }^{42}$ Das Andachtsziel wird nebenan bildlich vorgeführt und mit der direkten Aufforderung unter- 
stützt, den Schmerz des gekreuzigten Christus nachzuvollziehen. Für die verlangte compassio liefert die am vorderen Bildrand und damit der oder dem Betrachtenden am nächsten stehende zusammengesunkene Gottesmutter ein Vorbild. In umgekehrter Reihenfolge funktionieren die Inschriften ebenso. Der Schmerz, den Christus wegen der Sünden der Menschen durchlitten hat, fordert zu Mitleid und Reue auf und bewirkt die innere Ausrichtung (Herz und Hände) auf Gott, wie sie Gregor so vorbildhaft gelebt hat, dass ihm eine Vision zuteilwurde. Gleichzeitig ist der Mensch daran erinnert, die Gottesschau in der Messe, ermöglicht durch die Realpräsenz von Leib und Blut Christi in den eucharistischen Gaben, ${ }^{43}$ mit einer andächtigen Haltung zu erfahren. Beide Sätze sind demnach als Szenenanweisungen zu verstehen: Sie bilden neben den Bildern zusätzliche Andachtshilfen.

Während für die Kreuzigungsszene keine direkte Vorlage erschlossen werden kann, scheint die Gregorsmesse von einem Kupferstich des Meisters IAM von Zwolle (nachweisbar 1470-1495) beeinflusst zu sein und erhellt damit die Arbeitsweise der niederländischen Werkstatt (Abb. 3). ${ }^{44}$ Auf diesem hält Christus auch die Lanze und den Stab mit dem Essigschwamm im rechten Arm und weist mit der rechten Hand auf seine Seitenwunde. Mit dem linken Arm hält er die Geißelsäule umklammert, auf der der Hahn steht. Der um die Säule gewundene Strick ist auch in der Betnuss zu sehen. In der linken Hand hält der Schmerzensmann eine Rute und eine Geißel. Links und rechts vom Altar, stehen in lockerer Verteilung zwei Kardinäle und zwei Bischöfe mit denselben Utensilien wie in der Betnuss. Die Messdiener hinter Papst Gregor halten sehr lange Kerzen in den Händen, die mit den abgebrochenen Stäben in der Betnuss korrespondieren. Die Kerzenständer auf dem Altar stehen ebenfalls auf kleinen Füßen. Die zwei Köpfe unter dem rechten Kreuzarm in der Betnuss können mithilfe des Stichs als Judaskuss interpretiert werden. Selbst die Fransen des Fürlegers sind aus dem Stich in die Betnuss übertragen worden. Wie eng beide zusammengehören, erschließt sich über zwei weitere Schnitzereien aus der Werkgruppe. Es handelt sich um das schon genannte Diptychon im Metropolitan Museum of Art (Abb. 2) und einen Rundbogenanhänger im British Museum (Abb. 4). ${ }^{45}$ Aufgrund seiner Maße von 8,3 cm Höhe und $4,5 \mathrm{~cm}$ Breite (bezogen auf je eine Seite) sind in der Gregorsmesse des Diptychons noch mehr Details ausgearbeitet, die die Nähe zum Stich von Meister IAM von Zwolle zusätzlich unterstreichen. Abgesehen von der Haltung des Schmerzensmannes mit den ihm unmittelbar beigegebenen Passionswerkzeugen hängt der Rock Christi übereinstimmend über dem linken Kreuzbalken. Die im Stich dargestellte Marienfigur als Teil des Altarretabels, die gleichzeitig die Vision Gregors anzubeten scheint, ist in dem Diptychon an derselben Position innerhalb eines Retabels abgebildet, wenn auch von Christus abgewendet. Auf dem rechten Kreuzbalken sind in drei Stapeln die 30 Silberlinge dargestellt. Unter dem rechten Kreuzbalken ist der Judaskuss zu erkennen. Wie in der Hamburger Betnuss und dem Stich hält der vordere Bischof rechts vom Altar ein geöffnetes Buch in den Händen. Die Glocke in der Hand des linken Diakons oder Subdiakons in der Hamburger Betnuss taucht in dem New Yorker Diptychon beim rechten auf. Die Form der Kerzenständer auf dem Altar stimmt in beiden Schnitzereien überein. Der Anhänger in London nimmt mit einer Höhe von $6,4 \mathrm{~cm}$ und einer Breite von $4 \mathrm{~cm}$ die Position zwischen Hamburger Betnuss und New Yorker Diptychon ein. Auch diese Gregorsmesse lehnt sich an den Stich des Meisters IAM von Zwolle an. Er nimmt zusätzlich zur Verteilung aller Figuren und ihrer Beigaben aus dem Stich noch das Veronikatuch unter dem linken Kreuzbalken auf. Durch den Vergleich offenbart sich, dass in der Hamburger Betnuss neben dem rechten Fuß Christi die Salbgefäße angedeutet sind.

Die Reihe der Vergleiche ließe sich noch fortsetzen. Daraus lässt sich schließen, dass der Stich, wenn nicht die direkte Vorlage, so doch ein wichtiges Vorbild für die Gregorsmessen der drei Schnitzereien dargestellt haben muss. Erhärtet wird der Verdacht durch den Nachweis Evelin Wetters, dass die so genannte Magdalenennuss nach dem Tanz der Maria Magdalena von Lucas van Leyden gefertigt wurde. ${ }^{46}$ Die Gründe für die Orientierung an Kupferstichvorlagen liefert Jan Nicolaisen. Er zeigt auf, dass Kupferstecher Ende des 15. Jahrhunderts Bildstrategien entwickelten, die einem privaten Bedürfnis nach einer engen Betrachter-Bild-Beziehung nachkamen und dadurch zugleich ihre Produkte auf dem freien Markt günstig platzieren sollten. ${ }^{47}$ Darunter fielen das Close-Up, die Scharfzeichnung des Dargestellten, Bildgegenstände aus dem Alltag des Betrachters und eine Detailfülle, die in ihrer Gesamtheit "neue Möglichkeiten des Mitempfindens" boten. ${ }^{48}$ Demnach konnten mit der Kopie eines Kupferstichs in ein anderes Medium dessen Bildstrategien übernommen werden. Zugleich stellte die Schnitzerwerkstatt in der Übertragung eines großen Bildes in ein wesentlich kleineres ihre ungewöhnlichen Fähigkeiten auf eindrucksvolle Art unter Beweis. 


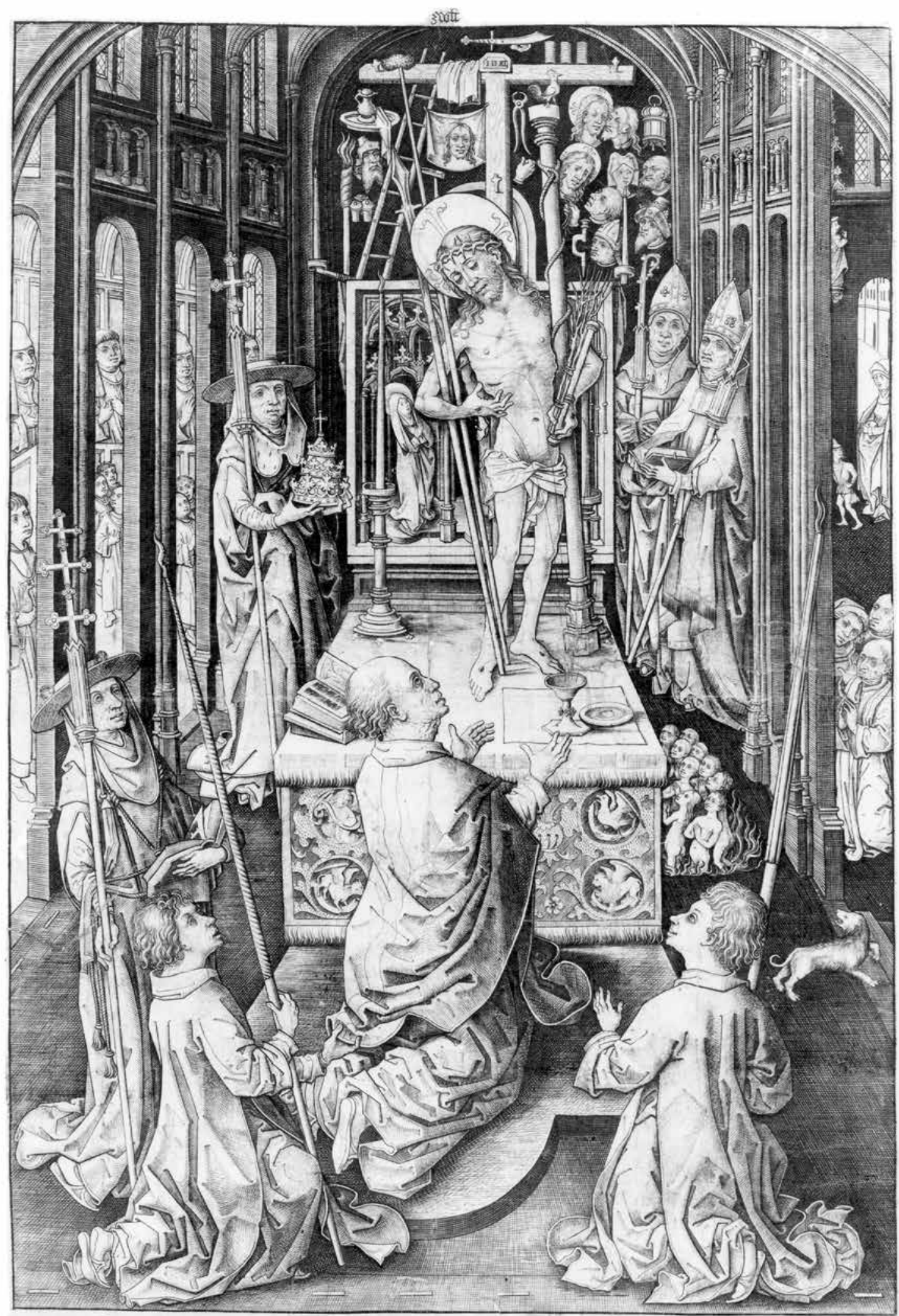

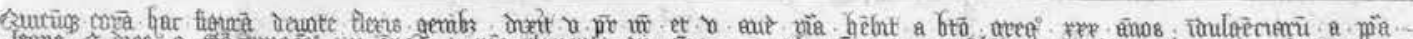

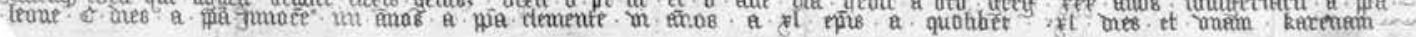

Abb. 3. Meister IAM von Zwolle: Gregorsmesse, drittes Drittel 15. Jh., 32,3×22,4 cm (Blatt). München, Staatliche Graphische Sammlung, Inv.-Nr. 1909:374 D (Foto: Staatliche Graphische Sammlung, München) 


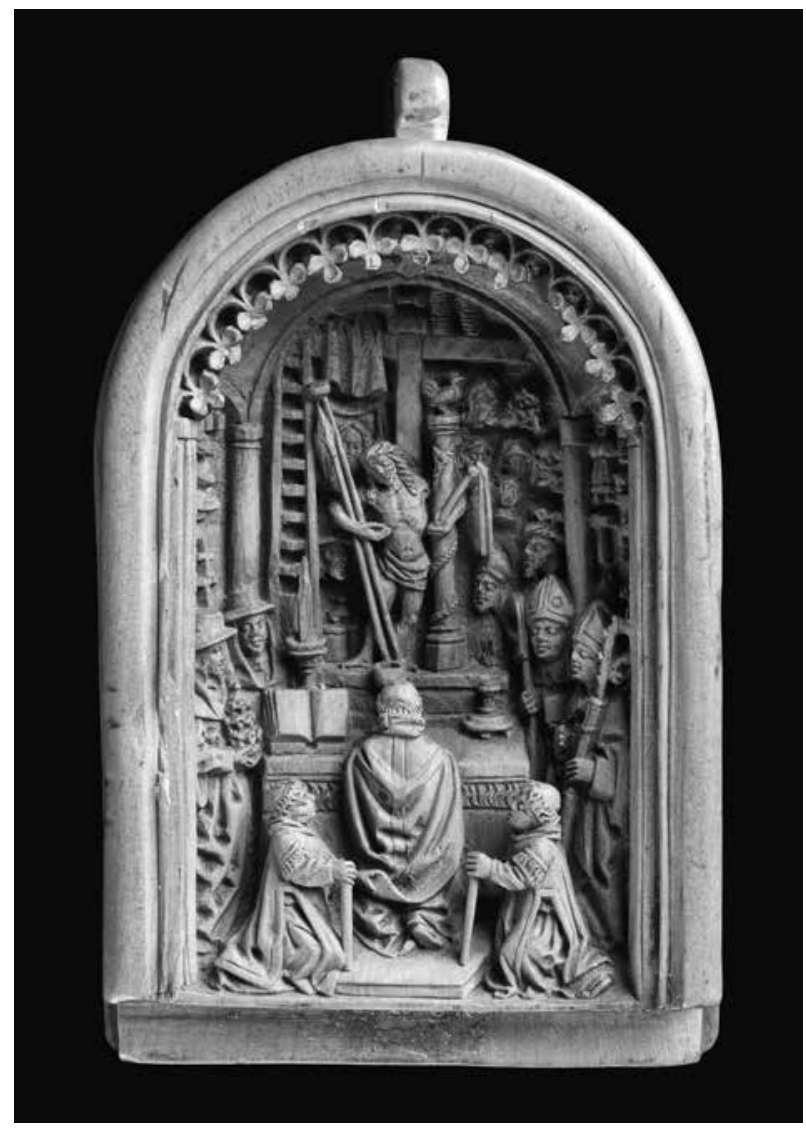

Abb. 4. Sog. Werkstatt des Adam Dircksz: Anhänger mit Gregorsmesse, 1500-1530, 6,4×4 cm

London, British Museum, Inv.-Nr. WB.241

(Foto: The British Museum, London)

Dem Inhalt der Betnuss begegnet der oder die Andächtige durch den Prozess des Öffnens mit gesteigerter Aufmerksamkeit. Der Akt des Öffnens scheidet die Bilder im Inneren der Betnuss von der Alltagssphäre und suggeriert, dass es hier um ein Geschehen geht, das nicht auf der Realitätsebene der oder des Betrachtenden stattfindet. Öffnen und Schließen können demnach als meditative Technik verstanden werden, die der Sichtbarmachung von sonst nicht Schaubarem dient. ${ }^{49}$

Die Diptychonform setzt die präsentierten Szenen zwangsläufig in eine Beziehung zueinander. Kreuzigung und Gregorsmesse stellen einen Zusammenhang her zwischen dem für die Menschen erbrachten Opfer Christi und der Erinnerung und Wiederholung dieses Opfers in der Messe. Dieser Zusammenhang wird durch eine Spiegelung im Zentrum unterstrichen: Christus ist jeweils ganzfigurig dargestellt, sein Kopf zu seiner Rechten geneigt. Seine Seitenwunde wird in der Kreuzigung durch die Abbildung des Lanzenstoßes betont, in der Gregorsmesse weist er mit seiner rechten Hand selbst darauf. Dass Christus sich in bei- den Szenen ungefähr an der gleichen Stelle befindet, nämlich in der oberen Mitte, macht die Kongruenz noch sinnfälliger. Marius Rimmele hat die Übereinstimmung von Körperhaltungen für Diptychen und Triptychen untersucht und vor allem das Zusammenklappen eines mehrteiligen Bildwerks als gedankliches Zusammenführen von Darstellungen gedeutet..$^{50}$ Die oder der Betrachtende würde auf diese Weise mit einer weiteren Sinndimension des Andachtsgegenstands bekannt gemacht, die sich im Schließen des Diptychons erst eröffne und gleichzeitig den Imaginationsprozess von außen nach innen verlagere. Übertragen auf das vorliegende Bildbeispiel erkennt die oder der Betrachtende eine Übereinstimmung der beiden Darstellungen Christi und blendet sie gedanklich übereinander. So erschließt sich, dass sich das historische Opfer Christi in der Messe wiederholt: Das von Christus für die Menschen vergossene Blut wird in der Wandlung der Sakramente immer wieder aufs Neue erinnert, ja sogar präsent gemacht.

Nicht zu vergessen ist, dass die Gregorsmesse ein Gnadenbild wiedergab, welches mit Ablässen verbunden war. ${ }^{51}$ Das Gebet vor dem Bild konnte demnach den praktischen Nutzen der Ablassgewährung haben und zwar ohne die Betrachtung des Originalbilds in Santa Croce in Gerusalemme. Zudem handelte es sich bei den zu sprechenden Gebeten neben den Orationes Gregorii um das Pater noster und das Ave Maria. ${ }^{52}$ Somit gelang der Übergang vom Beten des Rosenkranzes mit seinen alternierenden Mariengrüßen und Vaterunsern zur Betrachtung der Gregorsmesse mit seinen Ablassverheißungen fließend. Da auch das Beten des Rosenkranzes mit Ablässen versehen wurde, war es dem Gläubigen möglich, sein Heil mit nur einem Hilfsmittel zu quantifizieren. ${ }^{53}$ Die haptische Einbeziehung der oder des Rosenkranzbetenden durch das Berühren der Perlen wurde um die akustische Beschäftigung durch die gesprochenen Gebete ergänzt. Beide dienten als Untermalung für die Imagination der Rosenkranzgeheimnisse. ${ }^{54}$ Die Erweiterung dieses eigentlich schon wirksamen Andachtsinstruments um eine visuelle Komponente konnte den Blick noch einmal auf die richtigen, das heißt heilswirksamen, Bilder lenken. Die Betnuss setzte dabei eine Bewegungs- und Sprechpause in das rhythmische Beten des Rosenkranzes. Ihre Öffnung gab Bilder frei, die mit entsprechenden Inschriften zu einer weiteren Form der Andacht aufforderten. Aufgrund ihrer Kleinheit erschlossen sich der oder dem Betrachtenden die Bildzusammenhänge wohl Schritt für Schritt. Je öfter und intensiver die Person sie betrachtete, desto mehr 
Details erfasste sie und desto mehr Parallelen konnte sie zwischen den Darstellungen entdecken.

In der Länge der Beschreibung der Betnuss zeigt sich, dass allein eine Bestandsaufnahme des Dargestellten einen großen Raum einnimmt. ${ }^{55}$ Hier offenbart sich eine Bildstrategie. Die zur Andacht bereite Person öffnet die Betnuss und entdeckt darin einen Mikrokosmos. Aufgrund seiner Größe ist die oder der Betrachtende dazu gezwungen, die Betnuss nah an sich heranzuholen. In dem Versuch, alle abgebildeten Personen und Gegenstände zu erkennen, entsteht das Bedürfnis, in den Mikrokosmos hineinzukriechen - ein vorprogrammiertes Scheitern. Es baut sich ein Spannungsverhältnis zwischen der teils realistischen Darstellungsweise und der Kleinheit des Bildes auf, die zwangsläufig zu Verlusten in der Sichtbarkeit aller Details führt. So sind z.B. einige der Passionswerkzeuge in der Gregorsmesse genau zu identifizieren, die Altarmensa wird erkennbar von Paramenten bedeckt, das Geschirr der Pferde in der Kreuzigung und die Kleidung der versammelten Figuren entsprechen der zeitgenössischen Mode. Auch der Lanzenstoß und die Wundenweisung des Schmerzensmannes entgehen, so klein sie auch sind, dem Blick nicht. Andere Gegenstände entziehen sich jedoch dieser Detailschärfe. Die Augen der Abgebildeten bleiben kleine Punkte. Ihre Blickrichtung und den Ausdruck ihrer Gesichter muss die oder der Betrachtende imaginieren. Rückenfiguren können trotz ihrer Dreidimensionalität nicht gedreht und von der Vorderseite angeschaut werden. Hier wird die oder der Andächtige trotz eingehender Betrachtung keine vollständige Tiefenschärfe gewinnen. Ein Anfassen der Schnitzerei, um sich der erstaunlichen Feinheit der Miniatur haptisch zu versichern, verbietet sich aufgrund der Fragilität der teils nur wenige Millimeter großen Gegenstände. So fordert die Bildschnitzerei ein Anfassen heraus, verbietet es aber gleichzeitig. ${ }^{56}$ Sie erzeugt einen Mikrokosmos, der einen Überblick suggeriert, ${ }^{57}$ sich diesem aber gleich wieder entzieht durch die Unmöglichkeit, alles zu erkennen. Der Verzicht auf eine Fassung der Schnitzerei, die sicherlich auch technisch schwer umsetzbar gewesen wäre, fordert zur wortwörtlichen Ausmalung der Szene vor dem inneren Auge heraus. Nur angedeutete Details, z.B. unter den arma Christi, müssen ebenfalls von der andächtigen Person vervollständigt bzw. scharf gestellt werden. Fehlende Passionswerkzeuge ergänzt der oder die Betrachtende durch Imagination. Das angestrengte äußere Auge muss sich somit des inneren Auges bedienen, um ein befriedigendes tiefenscharfes Bild der Szene zu entwerfen. ${ }^{58}$ Die Betnuss erzeugt einerseits eine andächtige Haltung, indem sie allein für die Betrachtung und das Erkennen der Bildelemente ausschließliche und intensive Aufmerksamkeit einfordert. Die betrachtende Person verliert sich gleichsam in dem ihr offenbarten Mikrokosmos. Andererseits kann sie sich ihn doch nicht vollständig erschließen, sodass innere Bilder zur Ergänzung erzeugt werden müssen. Die Betnuss schafft auf diese Weise gleichzeitig Nähe und Distanz und verlangt zur Überwindung der Distanz eine Haltung, die meditativ auf das abgebildete Heilsgeschehen fokussiert.

\section{III.}

Das nächste Objekt ist ein Triptychon aus dem Brandenburger Domschatz (Abb. 5). ${ }^{59}$ Der Korpus besteht aus Holz und ist mit blauer Zendelseide beklebt. Während die Außenseiten der Flügel und die Rückseite des Korpus keine Bilder aufweisen, sind auf den Flügelinnenseiten Flachstickereien in Seide, Gold, Silber und Flussperlen sowie im Korpus eine Relief- und Flachstickerei in denselben Materialien angebracht. In den Kasten eingelassen ist eine Darstellung des Schmerzensmanns, der wie in der Hamburger Betnuss von einigen seiner Passionswerkzeuge umgeben ist (Abb. 6). Die Wappen links und rechts unten im Bild des Schmerzensmannes weisen darauf hin, dass das Objekt im Auftrag des Brandenburger Bischofs Joachim von Bredow (Bf. 1485-1507) entstanden ist. Der Einsatz der genannten Materialien verleiht der Stickerei höchste Kostbarkeit und verortet sie im Luxussegment des Privatbildes. Obwohl es bis heute Teil des Domschatzes ist, wird es keine liturgische Funktion gehabt haben, z.B. als Korporalkästchen, das - wenn überhaupt - nur flache Stickereien auf dem Deckel oder der Deckelinnenseite trägt. ${ }^{60}$ Das Wappen im Schmerzensmannbild ist nicht nur eine Dokumentation der Auftraggeberschaft Joachim von Bredows, sondern gewährt ihm durch seine Abbildung eine Teilhabe an der heilsgeschichtlichen Aussage. Er nimmt damit eine den Stifterfiguren ähnliche Position ein. Der Bischof bringt sich jedoch nicht als Figur ein, sondern auf heraldischem Wege und fügt sich damit gut in den Darstellungszusammenhang, denn das Wort arma meint nicht nur Waffen, sondern auch Wappen. Das Bredowsche Wappen korrespondiert also mit den das Wappen Christi repräsentierenden Passionsinstrumenten. ${ }^{61}$

Der Hintergrund zeigt einen Boden mit einem blau-gelben Schachbrettmuster in perspektivischer 


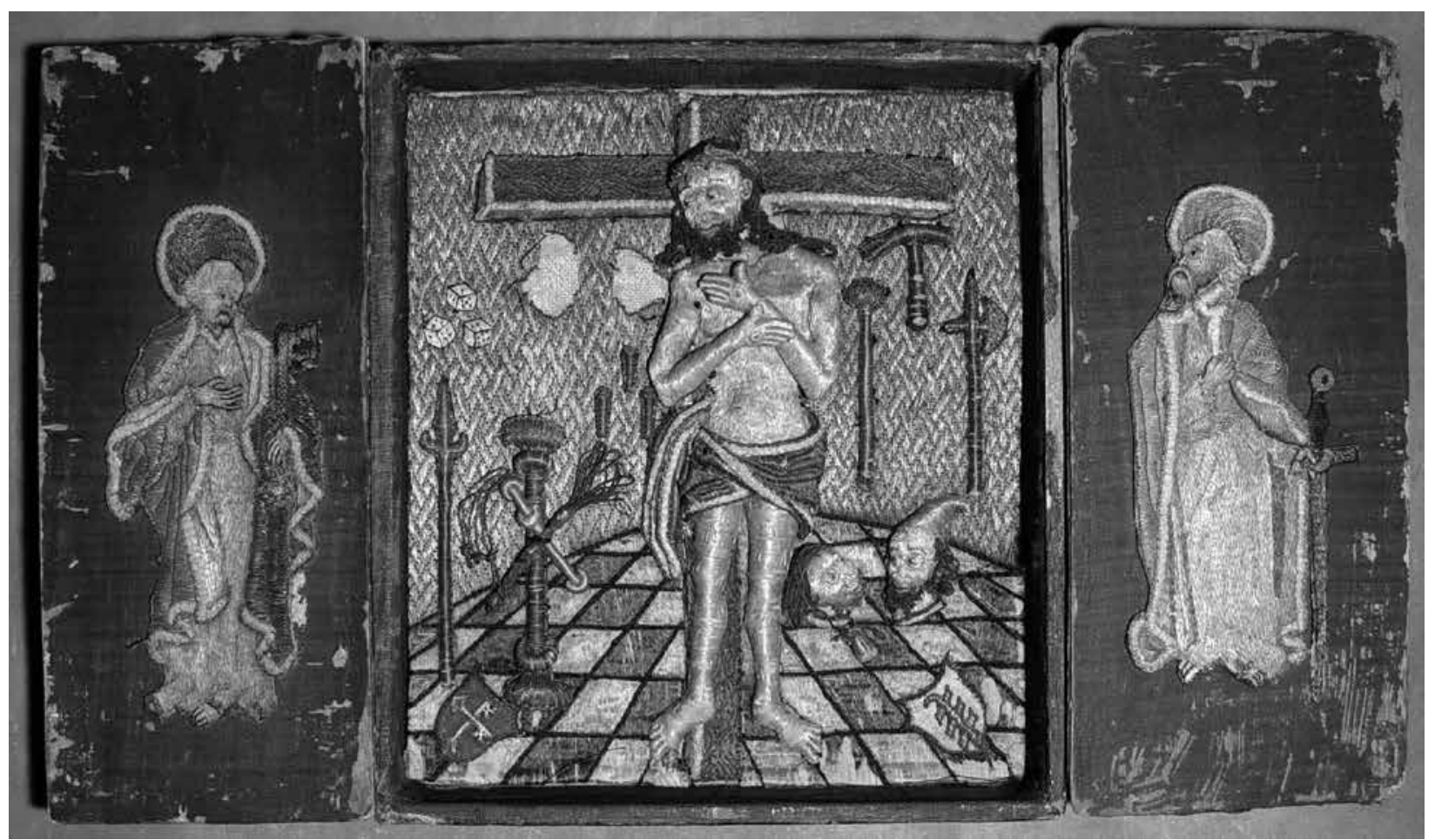

Abb. 5. Triptychon mit Schmerzensmann zwischen zwei Aposteln, 1485-1507, 25×22,1 cm (Kasten), 25×10,5-11,2 cm (Flügel). Brandenburg, Domschatz, Inv.-Nr. B 7 (Kasten) und B 6 (Flügel) (Foto: Domstift, Brandenburg)

Verkürzung und einen Grund aus Goldfäden mit roten Überfangstichen, die ein Flechtmuster bilden und dadurch einer gemusterten Tapete ähneln. Die arma Christi sind um den Schmerzensmann lose und ohne Bezug zum Raum angeordnet, sie erscheinen vielmehr frei schwebend. Sie sind größtenteils halbplastisch gearbeitet, treten also aus dem Bildgrund deutlich hervor. Zur Rechten Christi sind von innen nach außen die drei Nägel, die Geißelsäule mit Rute und Geißel, ${ }^{62}$ die Lanze und darüber die drei Würfel zu sehen. Zwei Aussparungen des Goldgrunds mit Resten schwarzer Fäden zwischen den Würfeln und dem Schmerzensmann zeigen an, dass dort ebenfalls Passionswerkzeuge angebracht waren, die allein anhand des Umrisses jedoch nicht identifiziert werden können. Zur Linken Christi sind von innen nach außen der Stab mit dem Essigschwamm, ein Hammer und eine Hellebarde angebracht. Alle metallenen Bestandteile der Passionswerkzeuge sind auch in Metall ausgeführt, überwiegend mit einem Silberfaden. Unterhalb von Schwamm und Hammer befinden sich zwei Köpfe. Der linke lässt sich durch den um seinen Hals gebundenen kleinen Geldbeutel und sein gelbliches Haar als Judas identifizieren. Im Zentrum schließlich steht der in heller Seide gestickte Christus vor seinem Kreuz. Da der Kreuzstamm weiter reicht als seine Füße und Christus selbst vollplastisch gear- beitet ist, scheint auch dieser in bzw. vor dem Raum zu schweben. Der Schmerzensmann kreuzt vor der Brust die Arme und wendet Kopf und Blick zu seiner rechten Seite. Durch die Drehung des Kopfes wird sein sehr überzeugend gearbeitetes linkes Ohr sichtbar - fast scheint es, er würde sich der oder dem Betrachtenden zuneigen, um Gebete zu empfangen und so in einen Dialog zu treten. Bekleidet ist er nur mit einem silbernen Lendentuch. Der Saum des Tuchs trägt eine goldene Borte und war ursprünglich mit Perlenwülsten verziert. Auf seinem braunen, gelockten Haar sitzt eine goldgrüne, mit Perlen verzierte Dornenkrone. Von der Krone läuft Blut auf die Nase des Schmerzensmannes. Sein Körper ist vollständig mit Wundmalen bedeckt. Obwohl sie mit einem horizontalen Seidenstich und drei davon strahlenförmig ausgehenden Stichen sehr schematisch angelegt sind, können sie leicht als Schnitte vorgestellt werden, aus denen Blut fließt. ${ }^{63}$ Die ursprünglich roten, heute verblassten Seidenfäden müssen den hellen Körper eindrucksvoll kontrastiert und ein eindrückliches Bild der Leiden Christi erzeugt haben. Hervorgehoben sind dabei die fünf wichtigsten Wunden Christi. Seine Füße und Hände zeigen kreisförmige, wulstige Male. Der rechte Arm Christi ist so geführt, dass er den Blick auf die Seitenwunde freigibt.

Auf den beiden Flügeln sind Petrus mit dem Schlüssel (Abb. 7) und Paulus mit dem Schwert (Abb. 8) 
abgebildet. Sie sind identisch ausgeführte Flachstickereien. Petrus und Paulus tragen lange gelbe Gewänder, unter deren Ende ihre nackten Füße hervorschauen. Ihre Mäntel und Nimben bestehen aus vergoldeten Silberfäden, das Mantelfutter ist blau. Mantelsäume und Nimbenränder waren ursprünglich mit Perlen besetzt. Das Inkarnat wurde mit schwarzen Konturen versehen. Die Überfangstiche für die Metallfäden sind im Zentrum der Nimben rot und zu den Rändern hin gelb. Die mit roten Stichen gezeichnete Linienführung des Faltenwurfs auf den Mänteln und auch die mit heller Seide ausgeführten Gewandfalten wirken etwas scharfkantig und schematisch. Dies lässt eine druckgraphische Vorlage für die beiden Figuren vermuten. ${ }^{64}$ Petrus und Paulus sind die Patrone des Brandenburger Domes, wodurch sich ihre Anwesenheit erklärt. Auf der Innenseite der Flügel erfüllen sie auch noch andere Funktionen: Sie vermitteln in die himmlische Sphäre, stehen der oder dem Betenden zur Fürbitte zur Verfügung und präsentieren auf einer metabildlichen Ebene den Schmerzensmann als zu betrachtendes Andachtsmotiv. ${ }^{65}$ Dass sie dabei ohne eigenen Hintergrund bleiben, erleichtert der betrachtenden Person den Übergang von ihrer in die Sphäre der Apostel. Ihr präsentiert sich im geschlossenen Zustand nur der dunkle Seidenbezug des Kästchens. Öffnet sie es, setzt sich der dunkle Stoff zunächst fort. Sie sieht die verweisenden Apostel und taucht in der Betrachtung der Mitte schließlich in einen Raum ein, der deutlich ihrer Sphäre enthoben ist. Die Figuren bereiten demnach einerseits das Bild des Schmerzensmannes vor, andererseits unterstreichen sie dessen Distanz.

Eine ungarische Stickerei in Form eines quadratischen Diptychons steht, wie schon von Evelin Wetter festgestellt, als nahsichtiges Andachtsbild der Brandenburger Stickerei am nächsten (Abb. 9). ${ }^{66}$ Für die plastische Wirkung der Köpfe Christi und Marias wurde die Stickerei auf einen aus Holz geschnitzten Untergrund aufgebracht. Das Gesicht Marias ist von Trauer gezeichnet. Ihre Stirn ist in Falten gelegt, die Augenbrauen sind zusammengezogen, über ihre Wangen laufen heute kaum noch erkennbare Tränen, ihre Augen sind gerötet, der Mund zieht sich zusammen. Aus dem Gesicht Christi scheint das Leben zu weichen. Die Dornen der Krone lassen Blut über seine Stirn laufen, die Nasenwurzel legt sich vor Schmerz in Falten, die Augenlider sind gesenkt, der Mund ist wie zu einem letzten Wort oder schmerzerfüllten Seufzer geöffnet. Die Augen bewirken einen Bewegungsimpuls bei der Betrachtung des Bildes, um den nach unten gehenden Blick aufzufangen. Beide Reliefstickereien

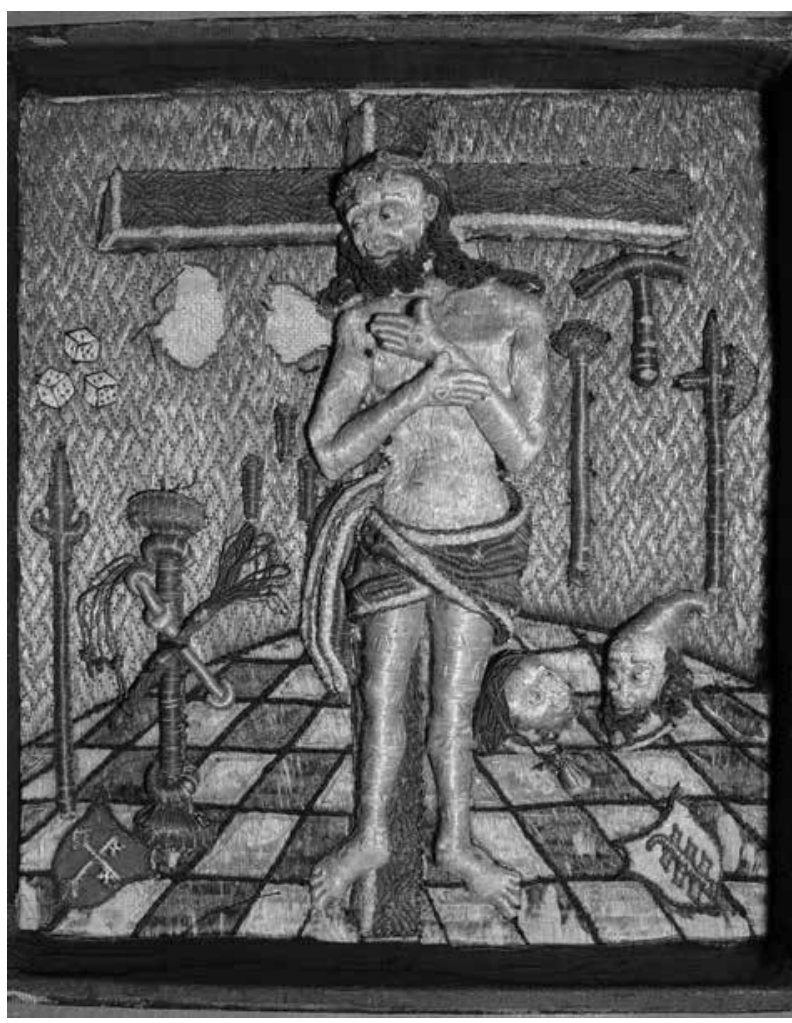

Abb. 6. Detail von Abb. 5 mit Schmerzensmann (Foto: Domstift, Brandenburg)

sind sehr fein und mit einem hohen Materialaufwand ausgeführt. Die Dornenkrone, bestehend aus Goldfäden und Flussperlen auf einem Träger, kommt dem Eindruck einer echten Dornenkrone äußerst nahe. Bei den Haupt- und Barthaaren Christi wurden einzelne seidenumwickelte Drahtgimpen in lockige Strähnen gelegt und nach Größe differenziert. So verläuft am Rand des Bartes auf der Wange eine Reihe feiner Stoppeln. Marias Schleier ist in Lasurtechnik gearbeitet und am Saum mit Flussperlen verziert. Beide Häupter erscheinen vor einem goldenen gemusterten Hintergrund. ${ }^{67}$ Hier verbindet sich eine hohe Reliefstickerei, die aus der Bildfläche hervortritt, mit einer extremen Nahsicht, die differenzierte Gesichtsausdrücke ermöglicht. Der Materialrealismus findet hier höchste Ausprägung, denn nicht nur Dornenkrone und Haare wirken lebensecht, sondern der Schleier und das Gewand Mariens bestehen wie echte, natürlich sehr prachtvolle, Kleidung aus Seide und Gold. Die Wahl eines hellen Seidengewebes für das Inkarnat unterstreicht zusätzlich die realistische Wirkung, da die weiche, das Licht absorbierende Oberfläche des Stoffs den Eindruck zarter glatter Haut erzeugt und damit einen Berührungsimpuls auslöst.

In der Brandenburger Stickerei (Abb. 5-6) liegt eine Betonung der Passionswerkzeuge mit dem 


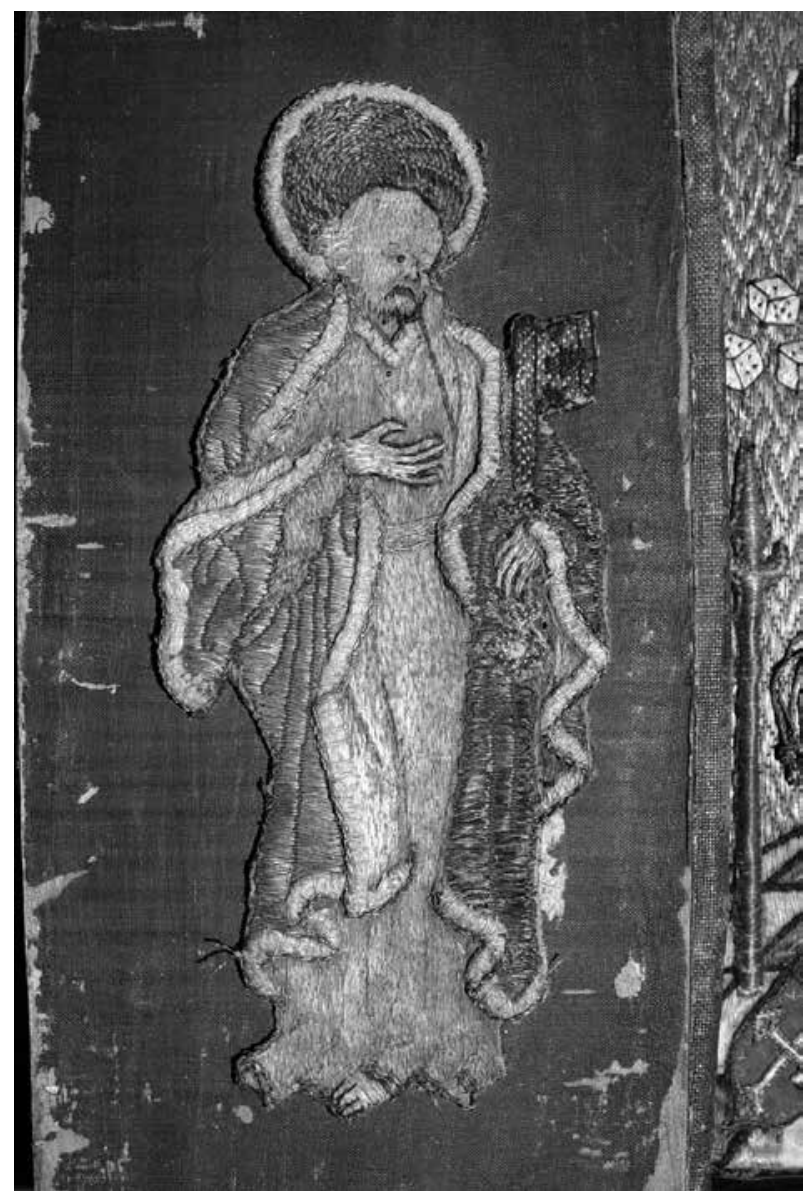

Abb. 7. Detail von Abb. 5 mit Apostel Petrus (Foto: Domstift, Brandenburg)

Schmerzensmann als Bezugsbild vor. Ursprünglich wurden die Waffen Christi als Zeichen verstanden, deren Erscheinen die Wiederkehr des Menschensohnes und das Jüngste Gericht ankündigte. ${ }^{68}$ Seit dem Hoch- und Spätmittelalter wurden sie, wenn sie nicht die eigentlichen Reliquien bezeichneten, im Sinne einer Passionsmeditation interpretiert. Die Wirksamkeit der andächtigen Betrachtung der Leidenswerkzeuge war durch Ablässe garantiert. ${ }^{69}$ Sie sind hier Erinnerungs- und Imaginationshilfen, durch plastische Ausführung und naturalistische Erscheinung verstärkt. Die arma Christi dienten nämlich als den Gläubigen verständliche Bildkürzel, die einzelne Stationen der Passion vor dem inneren Auge ablaufen ließen. ${ }^{70}$ Jörg Jochen Berns vergleicht die Betrachtung der arma Christi mit der Erzeugung eines inneren Films. ${ }^{71}$ Der Schmerzensmann inmitten der Passionswerkzeuge stellt dabei den Sinngehalt der einzelnen Gegenstände dar. Er drückt in der Vereinigung aller Einzelereignisse die Gesamtheit der Passion aus. Er ist in den durch die Leidenswerkzeuge kodierten Passionsszenen enthalten, die Instrumente ihrerseits haben Spuren auf dem

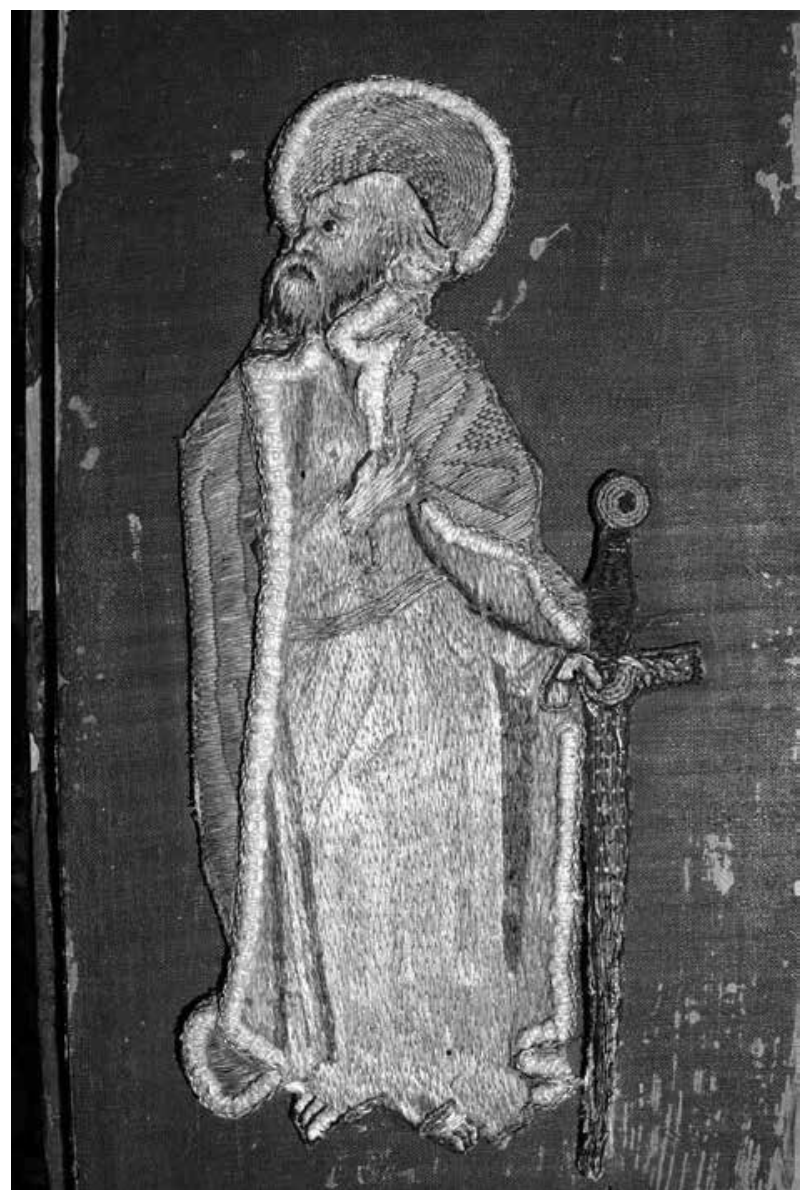

Abb. 8. Detail von Abb. 5 mit Apostel Paulus (Foto: Domstift, Brandenburg)

Körper Christi hinterlassen. Die arma Christi können auch als eine verdichtete Passionsfolge betrachtet werden, deren Entfaltung erst durch die imaginative Leistung des Betrachters erfolgt. Die einzelnen Werkzeuge helfen der Erzeugung innerer Bilder durch die Vorgabe äußerer. ${ }^{72}$ Die äußeren Bilder steuern dabei in gewisser Weise den Prozess und verhindern ein Abschweifen. Ihre unsystematische Anordnung gibt dabei keine Leserichtung vor und ist eine Strategie, die betrachtende Person zu beschäftigen: Sie selbst kann die richtige Reihenfolge der Motive und damit der Passionsszenen herstellen, indem sie ihren Blick kreisen lässt. Sie beschäftigt sich dadurch länger mit dem Bild als bei einer wohlgeordneten, leicht ablesbaren Übersicht. Suckale schreibt dazu: „[D]enn gerade daß das Bild zwar einen Mittelpunkt, aber keinen Anfang und kein Ende hat, daß der Blick es auf immer neuen Wegen absucht, ist der [...] Meditation nur förderlich. "73 Die fehlende Differenzierung nach Größe und räumlicher Position oder auch nach Bedeutung garantiert dabei eine gleichmäßige Nahsichtigkeit aller Leidenswerkzeuge. $^{74}$ 


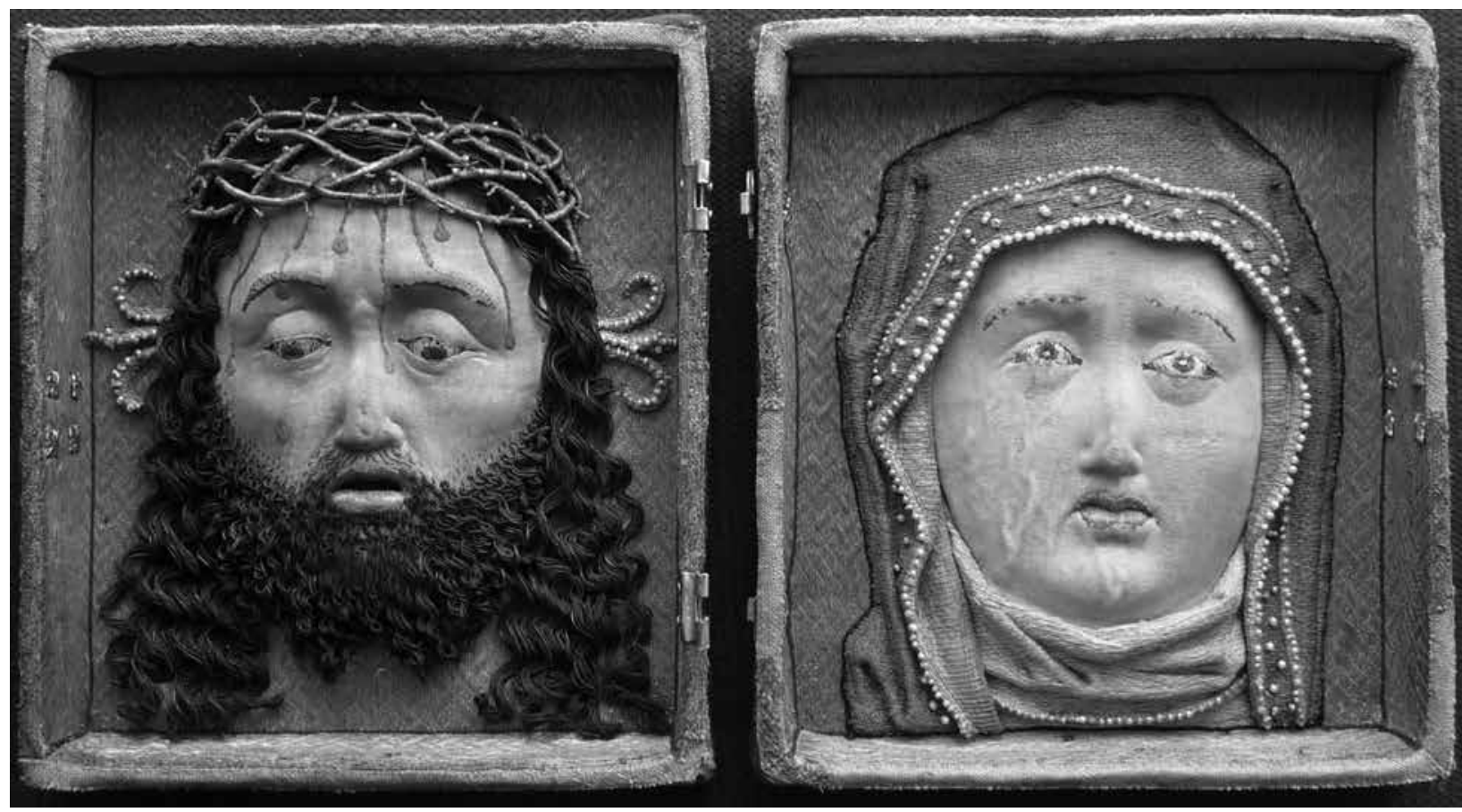

Abb. 9. Diptychon mit Schmerzensmann und Schmerzensmutter, um 1500, 20,7×18,5 cm. Esztergom, Főszékesegyházi Kincstár, Inv.-Nr. 1964.314.1,2 (Foto: Fôszékesegyházi Kincstár, Esztergom)

Welche weiteren Wirkstrategien entwickelt das Brandenburger Triptychon? Zunächst erfordert das kleinformatige Bild eine nahe Betrachtungsweise, um auch die kleineren Details zu erkennen. Der Hintergrund gibt dem Schmerzensmann und seinen Passionswerkzeugen zwar einen Raum und damit eine real wirkende Umgebung, aber gleichzeitig scheinen er und alle darin befindlichen Objekte davor zu schweben, weshalb sie auf die betrachtende Person nah wirken. Durch die Plastizität der Gegenstände intensiviert sich ihre Wirkung, sie rücken stark in den Vordergrund und werden damit regelrecht greifbar. Alle metallenen Teile der Passionswerkzeuge sind in Silberfaden ausgeführt, wodurch sie nicht nur realistisch erscheinen, sondern quasi das Material der echten Objekte imitieren. Auch in den Details stimmt der Eindruck von realen Gegenständen: Die Geißelstränge beispielsweise bestehen aus gezwirnten Silberfäden, die am Ende geknotet sind. Die oder der Betrachtende braucht nicht viel Vorstellungskraft, um sich die schmerzhafte Wirkung dieses Marterinstruments vor Augen zu führen. Der Schwamm mit unregelmäßig angeordneten gezwirnten Goldfäden, die mit beigefarbener und rotgelber Seide fixiert sind, ahmt die tatsächliche Struktur eines Schwamms nach. Das Kreuz weist ein mit Silberfäden gelegtes Muster auf, das trotz seiner Dekorativität und Regelmäßigkeit wie eine echte Holzmaserung wirkt.
Beide Apostel wenden sich dem Bild in der Mitte zu und lenken so den Blick der oder des Betrachtenden auf den Schmerzensmann (Abb. 5, 7-8). Hintergrund, Kreuz, Wappen und Würfel sind flach gestickt, die anderen arma Christi treten halbplastisch aus dem Bildgrund hervor. Der Schmerzensmann jedoch ist nahezu vollplastisch, sodass von den Flügeln bis in die Mitte des Korpus eine Steigerung der Plastizität stattfindet. Gleichzeitig zeigt sich im Schmerzensmann auch ein erhöhter Materialeinsatz: Sein Lendentuch weist viele tiefe Falten auf, über die Silberlahn gelegt ist. Die Kontur des Tuchs hebt sich von den übrigen Umrandungen in Goldfaden ab, da hier ein Zwirn von dreimal drei Metallfäden vorliegt. So unterstreicht das Material zusätzlich die Bedeutung der zentralen Figur des Schmerzensmannes. Er ist nicht nur der plastischste Teil des gesamten Andachtsbildes, sondern auch der gemessen an seiner Nacktheit materialintensivste. Auch in der Größe Christi drückt sich gegenüber den kleineren Apostelfiguren eine bildinterne Hierarchie aus. Die oder der Betrachtende wird damit über die Figuren an sich sowie ihre Größe und Ausarbeitung ins Zentrum geleitet. Marius Rimmele hat eine solche Abstufung des Materials an einem triptychonförmigen Reliquienanhänger im Amsterdamer Rijksmuseum demonstriert (Abb. 10-11). ${ }^{75}$ Von gravierten Heiligendarstellungen auf den Flügelaußenseiten über die flachen Emails der Flügelinnenseite gelangt man 
Betrachter zum émail en ronde bosse der Engelpietà in der Mitte. ${ }^{76}$ Die Strategie der Blicklenkung und Wahrnehmungssteigerung von einfach bis elaboriert und von flach bis plastisch war eine der Triptychonform innewohnende Möglichkeit und fand auch in den großen Altarretabeln Anwendung. Dass der Anhänger wie auch das Brandenburger Triptychon außen keine Darstellungen aufweist, muss nicht als Defizit gewertet werden. Das schlichte Äußere intensiviert die Wirkung des Inneren: Gleich einer Epiphanie erscheinen vor der oder dem Betrachtenden die Figuren. ${ }^{77}$

Durch die Vollplastizität des Schmerzensmannes und seine Platzierung vor dem Bildraum entsteht der Eindruck, dieser könne wie eine Puppe aus dem Kästchen herausgenommen werden. Aufgrund seiner Verankerung im Stickgrund funktioniert dies natürlich nicht. Das Ende des um den Körper geschlungenen Lendentuchs hängt lose am rechten Bein Christi und verführt zu dem Versuch, das Lendentuch ordentlich um den Christuskörper zu wickeln ${ }^{78}$ - auch dies ist nicht möglich. So wird wiederum ein Spannungsverhältnis erzeugt zwischen der Nähe, die zum Berühren einlädt und der Distanz, die in der Unerfüllbarkeit der Berührung entsteht. Trotz der haptischen Qualität der Darstellung verbietet sich nämlich ein Anfassen der kostbaren Stickerei. Sie hält den Betrachter zwischen taktilem Reiz und Unberührbarkeit gefangen. Die weiche Seide am Christuskörper und seine Puppenhaftigkeit suggerieren eine Verfügbarkeit, die zugleich eine Illusion ist, denn die Christusfigur bleibt mit dem Bildgrund verbunden und stellt sich beim Berühren nicht als weich und manipulierbar, sondern als fest und starr heraus. Ähnlichkeit ist noch keine Echtheit. Die Überwindung dieser Distanz bleibt wiederum der andächtigen Person und ihren inneren Bildern überlassen. Sie ergänzt fehlende Passionswerkzeuge und kann nur in einer Vision wie der Bernhards von Clairvaux darauf hoffen, mit Christus in Interaktion zu treten. ${ }^{79}$

IV.

Das dritte Objekt ist der Schmerzensmann des sogenannten Meisters Francke im Leipziger Museum der bildenden Künste (Abb. 12) ${ }^{80}$ Als Bildträger dient eine 42,5 cm in der Höhe und $31,3 \mathrm{~cm}$ in der Breite messende Eichenholztafel. Damit ist sie für einen kirchlichen Gebrauch, etwa als Altarbild, entschieden zu klein. Datiert wird das Werk in die Zeit um 1420, beruhend auf der fragwürdigen Biographie des im Grunde immer noch völlig unbekannten und wahr- scheinlich nicht Francke genannten Meisters. Möglicherweise ist das Bild schon um 1400 entstanden. ${ }^{81}$ Vor einem Goldgrund erscheint Christus als Schmerzensmann in Halbfigur. Gehalten wird er von einem großen Engel, weshalb diese Darstellung - ebenso wie die des Amsterdamer Reliquienanhängers ( $A b b$. 10-11) - als Engelpietà bezeichnet werden kann. ${ }^{82}$ Flankiert wird die Zweiergruppe von zwei kleineren Engeln, die Christi Arme stützen und gleichzeitig verschiedene, im Verhältnis zum Schmerzensmann miniaturisierte arma Christi tragen, ähnlich wie in der Brandenburger Stickerei. Der linke Engel hält den Stab mit dem Essigschwamm, die Lanze und eine Rute, die er Christus in die rechte Hand zu geben scheint, deren Finger gleichzeitig die Seitenwunde umschließen und unterstreichen. Der rechte Engel trägt die Geißelsäule und gibt Christus die Geißel in die Hand, doch wirkt sie zu schwach, um sie richtig zu fassen. Am Kreuz ist der Kreuztitel INRI wiedergegeben. Im Kreuz stecken die blutigen Nägel. Blut läuft auch von der Dornenkrone auf dem Haupt Christi herab, aus seiner Seitenwunde bis zum Schleier, mit dem seine Mutter Maria nach der Entkleidung seine Blöße bedeckte. Die Wunden an den Händen sind ebenso sichtbar, der Engel zur Rechten Christi scheint mit seiner rechten Hand sogar die Wunde zu berühren - ein besonders haptisch wirkendes Detail.

Der leichenblasse Körper Christi und sein Kopf zeichnen eine leicht nach links gebogene Linie nach, während der nach rechts geneigte, mit einem rosigen Teint versehene Kopf und die Flügel des großen Engels eine genau entgegengesetzte Linie andeuten. Die Körperlinien unterstreichen den Kontrast. Sie sind auch in dem Reliquienanhänger zu erkennen. Ebenso komplementär sind Haltung und Kleidung der kleinen Engel angelegt: Der linke ist mit dem Rücken zu der oder dem Betrachtenden gestellt und wendet seinen Kopf zu Christus nach oben. Er trägt einen roten Mantel mit grünem Innenfutter. Der rechte Engel befindet sich in einer seitlichen Position und hat den Kopf nach unten gedreht. Sein Überwurf ist grün und weist ein rotes Futter auf. Mit ihren Flügeln und ihren Körpern schließen sie das Bild zu den unteren Seiten und zum unteren Bildrand hin ab. Der obere Bildrand wird optisch vom Querbalken des Kreuzes abgeschlossen. Die verbleibenden oberen Seiten finden ihre Begrenzung in den nach vorn gedrehten Ellenbogen Christi und den Flügeln des großen Engels. Die Komposition scheint somit einen Raum zu erschließen, ohne jedoch Räumlichkeit im eigentlichen Sinne zu konstruieren. Der Bildcharakter der Darstellung findet darin - wie 


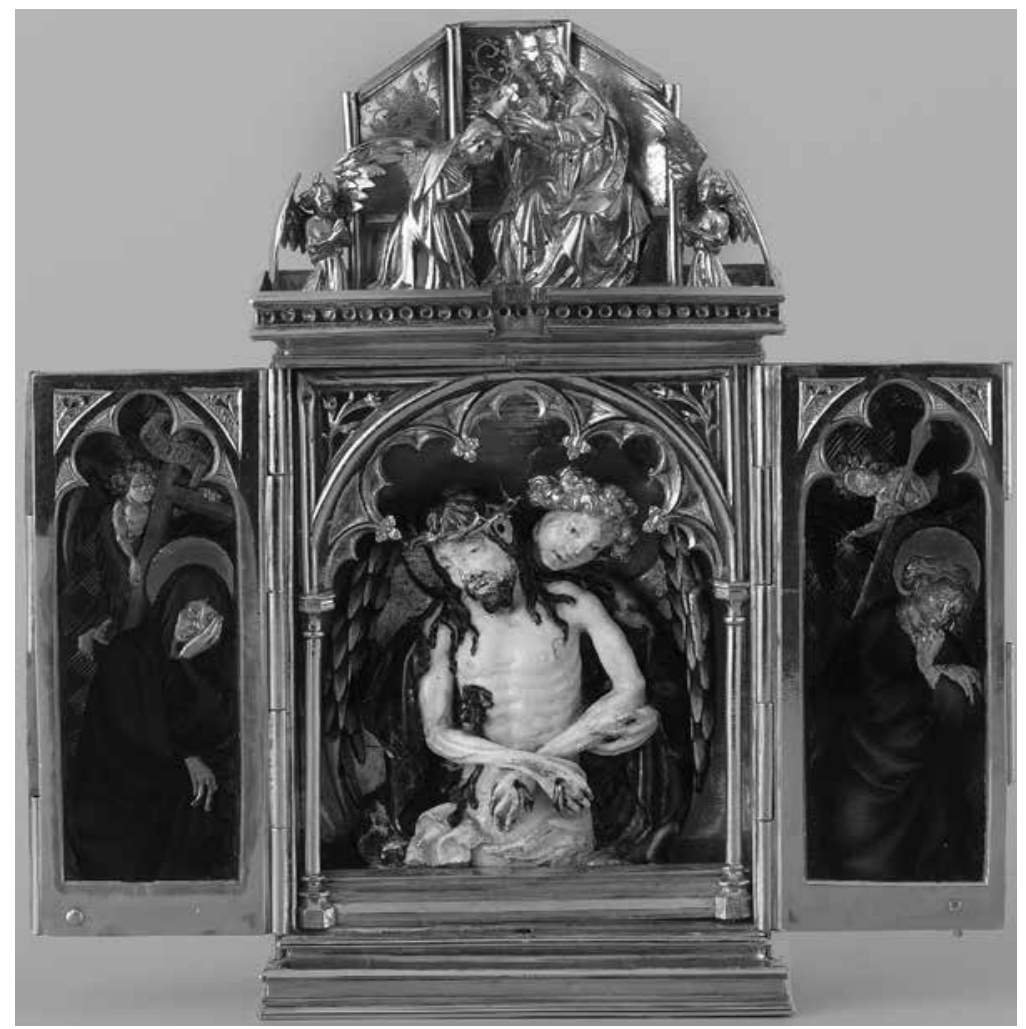

$A b b$. 10. Reliquiar in Form eines Triptychons mit Engelpietà zwischen Maria und Johannes, um 1400-1410, 12×12,7 cm (geöffnet). Amsterdam, Rijksmuseum, Inv.-Nr. BK-17045 (Foto: Rijksmuseum, Amsterdam)

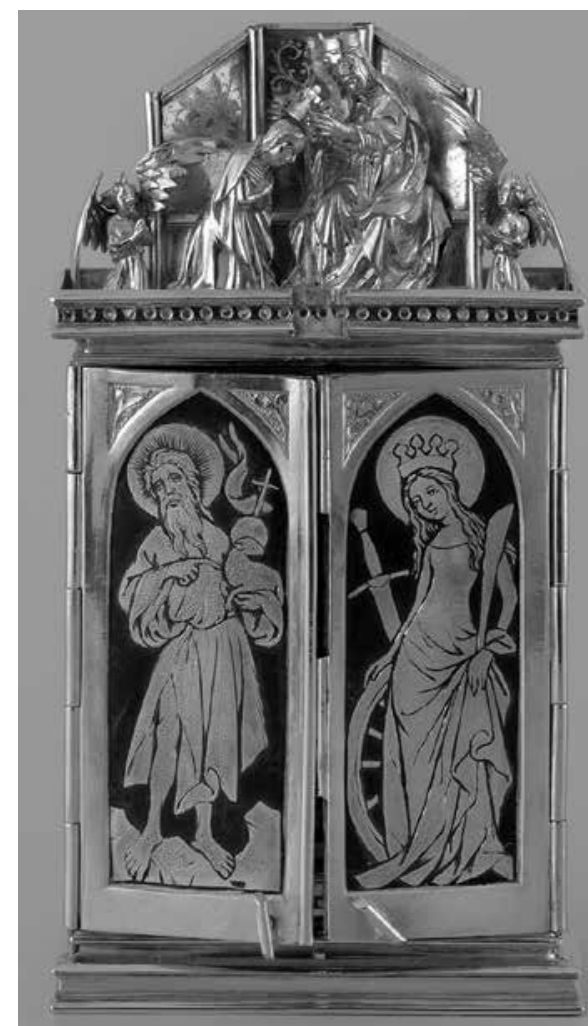

Abb. 11. Geschlossene Ansicht des Reliquiars auf der Abb. 10

(Foto: Rijksmuseum, Amsterdam) auch in der Präsentation Christi in der Vorwärtsbewegung des Engels - seine Verdeutlichung. Zudem fordern die gedrängte Komposition und das kleine Bildformat die betrachtende Person dazu auf, einen nahen Standpunkt einzunehmen.

Der Goldhintergrund zeigt am Bildrand eine punzierte Zierleiste. Am Haupt Christi sind die punzierten Strahlen eines Nimbus erkennbar. Der Hintergrund erhält durch das wie in einem Rapportmuster angelegte punzierte Christusmonogramm ihs das Aussehen eines wertvollen Textils, das die gesamte Darstellung hinterfängt. Zudem wirkt das Monogramm wie ein Impuls, den Namen auszusprechen und die Bildbetrachtung um eine auditive Komponente zu erweitern - neben möglicherweise ohnehin gesprochenen Gebeten.

Der Rahmen der aus einem Stück gefertigten Holztafel weist von außen nach innen gehend eine flache vergoldete Leiste und eine dunkelblaue Kehle auf, sodass die eigentliche Bildfläche wie in einer Vertiefung liegt. Beide - Rahmen und Kehle - wurden nachgearbeitet: Die goldene Rahmenleiste weist noch Reste einer Punzierung auf, die mit der Neuvergoldung fast gänzlich verschwand. Unter dem stumpfen Dunkelblau der Kehle liegt eine Schicht Azurit. ${ }^{83}$ Der blauen
Kehle sind 24 vergoldete filigrane Metallrosetten aufgesetzt. ${ }^{84}$ Die Rosen können in einem Andachtszusammenhang als Anspielung auf die gesprochenen Gebete des Gläubigen verstanden werden bzw. als Aufforderung zum Sprechen von Gebeten. ${ }^{85}$ Diese Symbolik wird im Rosenkranz, dessen Verehrung und Institutionalisierung im Laufe des 15. Jahrhunderts zunimmt, ihren deutlichsten Ausdruck finden. Das Gebet des Gläubigen materialisiert sich in Rosen, die zu einem Kranz geflochten werden. ${ }^{86}$ Die Plastizität der Rosetten beschäftigt zusätzlich den haptischen Sinn der oder des Betrachtenden und zieht damit auf einer weiteren Ebene die Aufmerksamkeit auf das Bild. Gleichzeitig ist ihre kostbare Erscheinung kaum eine Einladung zu permanenter Berührung, sondern erzeugt eine gewisse Spannung zwischen dem Wunsch, die visuell wahrgenommene Plastizität mit den Händen zu überprüfen, und den Abnutzungserscheinungen, die eine solche Handlung mit sich bringen würde.

Der große Engel berührt den Körper Christi nicht mit bloßen Händen, sondern durch einen zarten Schleier. Dieses Detail ist auf dem Reliquiar des Rijksmuseums ebenfalls zu finden, aber auch in den genannten Miniaturen und in einer oberrheinischen 


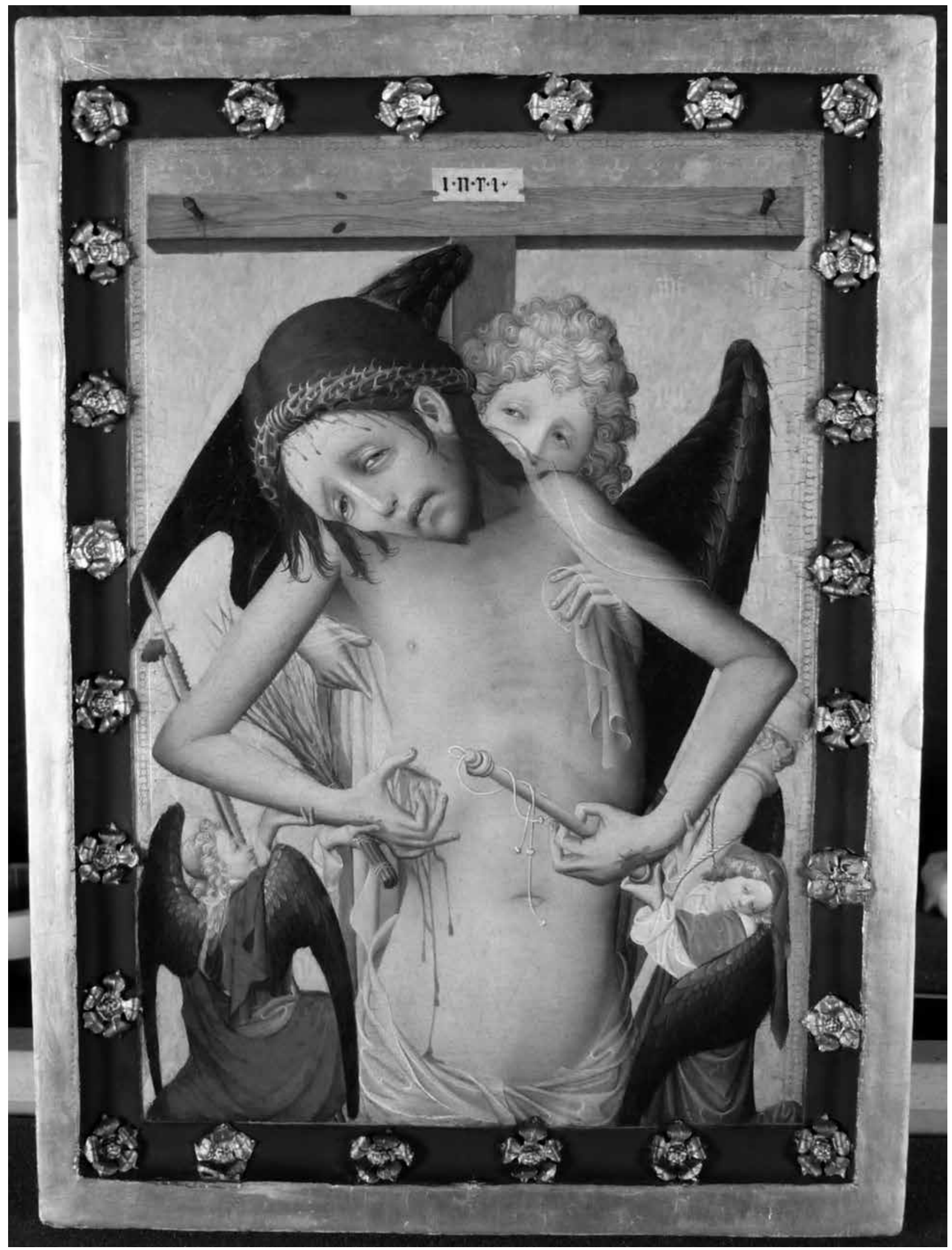

Abb. 12. Sog. Meister Francke: Schmerzensmann, erstes Viertel 15. Jh., 42,5×31,3 cm.

Leipzig, Museum der bildenden Künste, Inv.-Nr. 243 (Foto: Museum der bildenden Künste, Leipzig) 
Skulptur, in der Engel und Schmerzensmann ähnlich wie im Reliquiar und auf der Tafel angeordnet sind. ${ }^{87}$ Die Geste erinnert an die Elevation der gewandelten Hostie in der Messe. Das Tuch zwischen dem Körper Christi und dem Engel evoziert in diesem Sinne die Assoziation mit dem Korporale, das dem Kelch und der Patene als Unterlage auf dem Altar dient. Diese Form der Darbietung hat Gert von der Osten und Wiltrud Mersmann dazu veranlasst, den großen Engel als angelus Missae zu bezeichnen, während Rudolf Berliner dagegenhält, der angelus Missae sei nach Thomas von Aquin (1225-1274) Christus selbst und die Bezeichnung beruhe eher auf dem Bedürfnis einer theologischen Rechtfertigung des Motivs. ${ }^{88}$ Ob nun diese Bezeichnung zutreffend ist oder nicht, können der oder die Engel grundsätzlich als im Messgeschehen Mithandelnde interpretiert werden: Sie bringen die vom Priester dargereichten Gaben in den Himmel, wo sie von Gott gewandelt und wieder zum Altar zurückgebracht werden. ${ }^{89}$

Auf der Rückseite der Leipziger Tafel ist eine durch starke Gebrauchsspuren schlecht erhaltene vera icon zu erkennen (Abb. 13), das Bildnis Christi, wie es sich in das Schweißtuch der heiligen Veronika einprägte. ${ }^{90}$ Dass die vera icon aber aus derselben Zeit und von derselben Hand stammt wie der Schmerzensmann, ist wahrscheinlich. ${ }^{91}$ Insgesamt ist diese Malerei im Aufwand wesentlich schlichter. Der rote Untergrund besteht lediglich aus einer Kreidegrundierung, Mennige und einer Kermeslasur. ${ }^{92}$ Die goldenen Nimbusstrahlen sind transparent im Gegensatz zum Gold der Vorderseite. Eine Abstufung des Materialaufwands ist - ähnlich wie in der Brandenburger Stickerei - also auch in dieser Arbeit zu erkennen. Sie ist hier einerseits pragmatisch zu begründen, denn die Rückseite war als Außenseite viel stärker einer Abnutzung ausgesetzt und die Bemalung diente als Schutz gegen Feuchtigkeit ${ }^{93}$ andererseits unterstützte sie aber auch eine bildinterne Hierarchisierung und Lenkung des Blicks von der einfachen Malerei der Außenseiten zur material- und hinsichtlich der verwandten Techniken auch zeitintensiveren Malerei der Innenseiten.

Ein etwas älteres kölnisches oder westfälisches Tafelbild zeigt auf der Rückseite eine ähnlich gestaltete vera icon (Abb. 14-15): Der Bart ist zweigeteilt, die Haare fallen in zwei großen Strähnen seitlich herab, am Scheitel, zwischen den Bartspitzen und jeweils auf der Mitte der Seiten sind Nimbenstrahlen gemalt. ${ }^{94}$ Auch der Goldschmiedeanhänger aus dem Rijksmuseum weist auf seiner punzierten Rückseite genau an der Stelle, wo sich die kleine Öffnung für die Reliquie

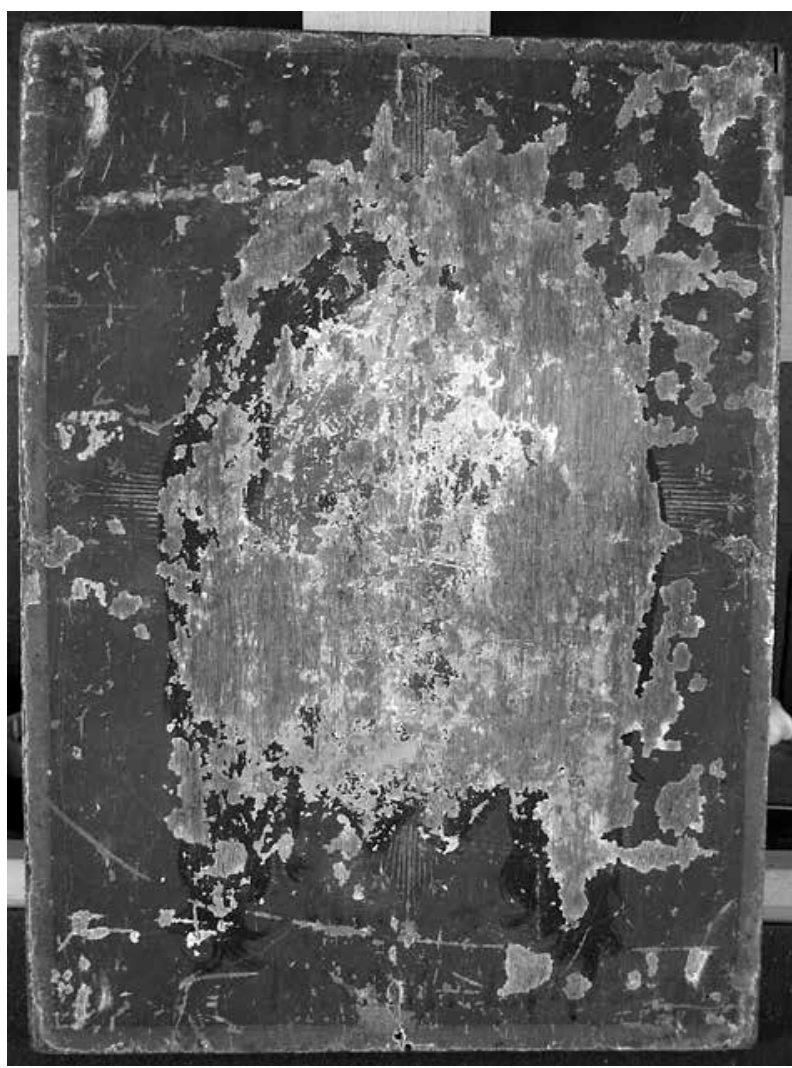

Abb. 13. Rückseite des Gemäldes auf der Abb. 12 mit vera icon (Foto: Museum der bildenden Künste, Leipzig)

befindet, eine vera icon auf. Die Verbindung dieser beiden Bilder war demnach nicht ungewöhnlich. Darüber hinaus war das Veronikabild häufig Teil der arma Christi, versinnbildlichte aber auch allein den leidenden Passionschristus und konnte auf einer weiteren Bedeutungsebene als Reliquie in der römischen Kirche St. Peter eines der schaubaren Bilder Christi sein.

Die Tafel in Leipzig weist am seitlichen Rand Löcher auf, die auf eine ehemalige Verbindung mit einem weiteren Bild schließen lassen. Der rechte Seitenrahmen zeigt noch Spuren eines Hakenverschlusses, der linke ist im Gegensatz zur roten Fassung der übrigen Seiten holzsichtig (Abb. 16-17). Eine Ausmessung zeigt, dass diese Seite abgehobelt worden ist, denn sie ist gegenüber der rechten Seite um 0,5 cm kürzer..$^{95}$ Es ist also wahrscheinlich, dass hier ein Scharnier entfernt wurde und deshalb nicht mehr zu erkennen ist. Die zuvor beschriebene Vertiefung des Bildspiegels macht eine ursprüngliche kastenförmige Verschließung zusätzlich möglich. ${ }^{96}$ Es gibt also einige Indizien, die gegen die ursprüngliche Existenz des Bildes als Einzeltafel sprechen.

Das Schmerzensmannbild kann demnach als Teil eines Diptychons gedacht werden..$^{97}$ Ein solches befin- 


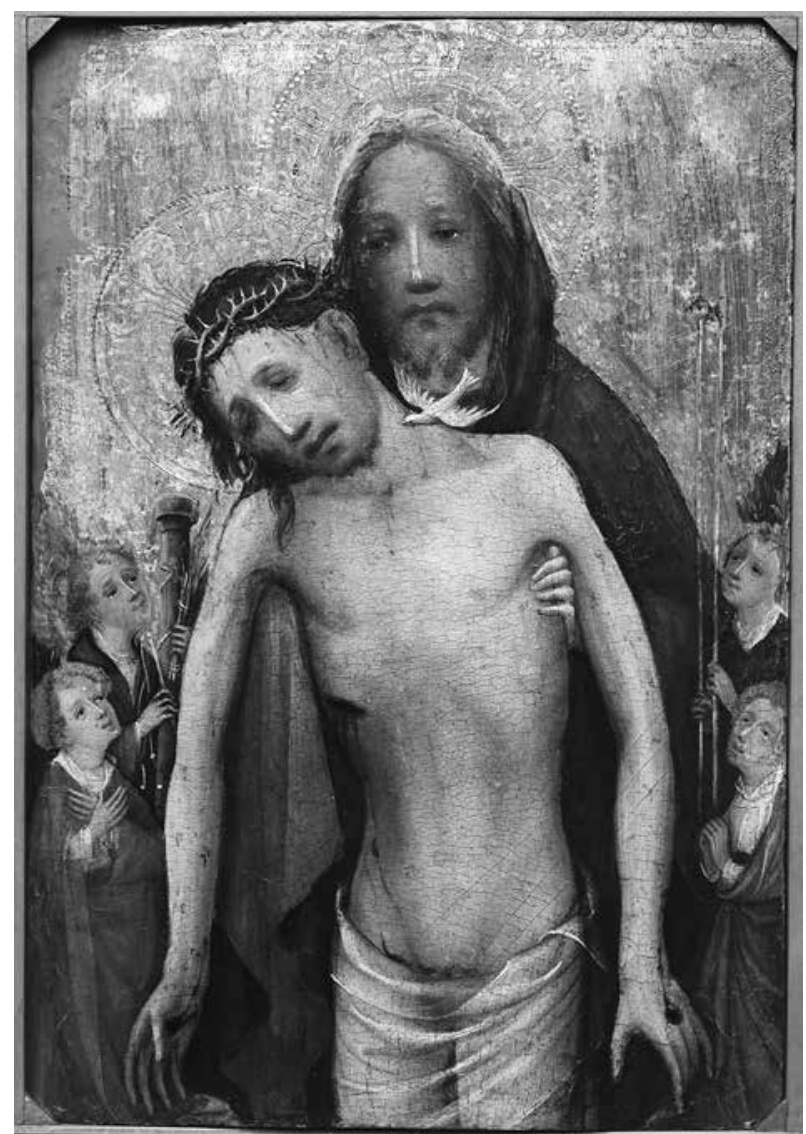

Abb. 14. Meister von St. Laurenz: Notgottes, um 1415 , 23,2×15,7 cm. Köln, Wallraf-Richartz-Museum und Fondation Corboud, Dep. 0363 (Foto: Rheinisches Bildarchiv, Köln, rba_c002067)

det sich in der Karlsruher Kunsthalle. ${ }^{98}$ Es zeigt auf der rechten Tafel den Schmerzensmann und auf der linken eine Madonna mit dem Kind, das an die mütterliche Wange greift. ${ }^{99}$ Beide Bilder fanden in Böhmen, woher das Karlsruher Diptychon stammt, in dieser Kombination eine hohe Verbreitung. Sie waren über die Vermittlung Italiens von byzantinischen Ikonen beeinflusst. Ein italienisches Exemplar, das Madonna und Kind mit dem Schmerzensmann kombiniert, ist das Diptychon von Pietro Lorenzetti im Museum Lindenau in Altenburg. ${ }^{100}$ Der Schmerzensmann als Sinnbild der gesamten Passion und der Erlösungstat Christi wird dadurch mit seiner Menschwerdung verbunden, die zu diesem Zwecke geschah. Zugleich markieren beide Darstellungen Anfangs- und Endpunkt des Lebens Jesu. Die Menschwerdung ist die Voraussetzung für das Erlösungsopfer. Das Jesuskind wird in vielen Darstellungen mit Symbolen seiner zukünftigen Leiden versehen, weshalb der Schmerzensmann ein figürlich ausgearbeiteter Hinweis auf die Passion ist. So eng beide Darstellungen miteinander verbunden

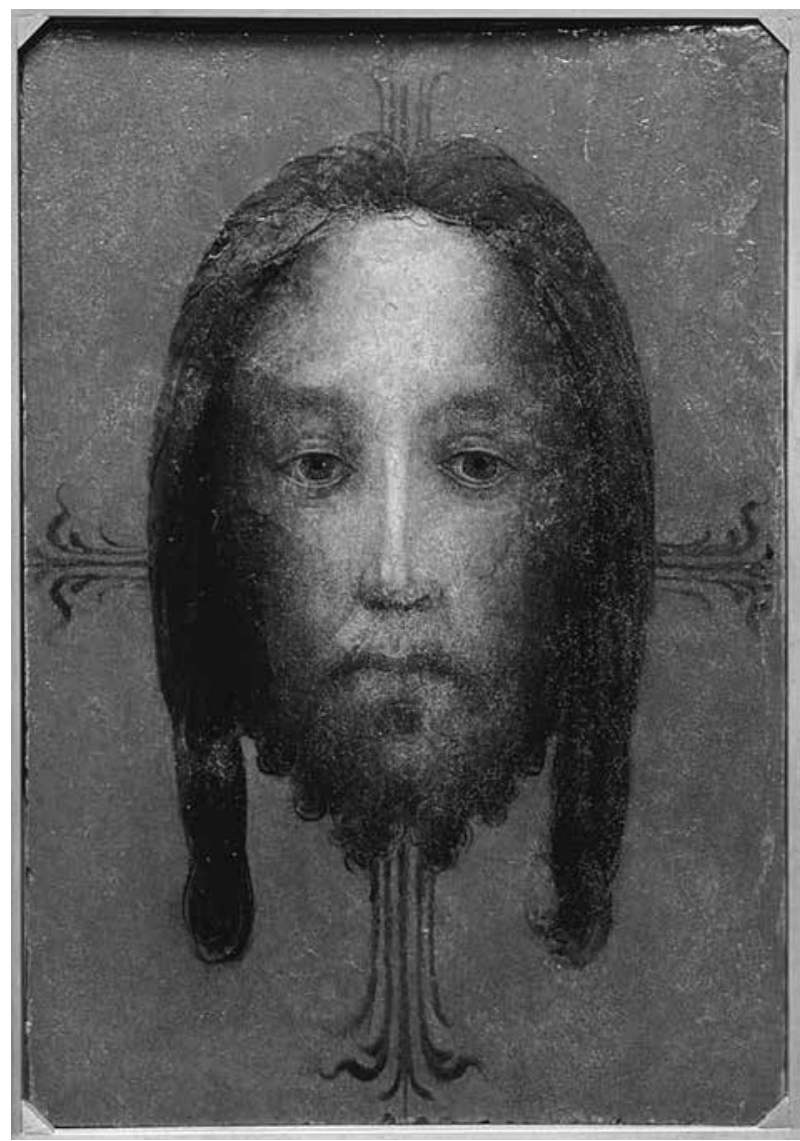

Abb. 15. Rückseite des Gemäldes auf der Abb. 14 mit vera icon (Foto: Rheinisches Bildarchiv, Köln, rba_c001186)

sind, können sie jedoch auch antithetisch aufgefasst werden: ${ }^{101}$ die Menschwerdung als freudenreiches Ereignis, die Passion als schmerzensreiches. Darüber hinaus wird in Zusammenhang mit der Abbildung Mariens, die das Jesuskind auf dem Schoß hält, ihr Anteil am Erlösungswerk deutlich. Für den Leipziger Schmerzensmann kommt somit aufgrund des Befunds eine Kombination mit einer weiteren Bildtafel, möglicherweise einer Madonna mit Kind, infrage.

Das zweite Schmerzensmannbild aus der Hand desselben Meisters in der Hamburger Kunsthalle sei kurz erwähnt (Abb. 18). ${ }^{102}$ Es wird als Spätwerk des Malers angesehen. Da es etwas mehr als doppelt so groß wie das Bild in Leipzig ist, macht es einen weniger privaten Eindruck. ${ }^{103}$ Der Schmerzensmann ist hier von mehreren kleinen Engeln begleitet, die das hinter ihm aufgespannte Ehrentuch und seinen außen weißen und innen roten Mantel halten. Zwei Engel am unteren Bildrand halten jeweils das Flammenschwert und die Lilie - sie präsentieren Christus somit als den Weltenrichter am Jüngsten Tag. Der Körper Christi ist viel 


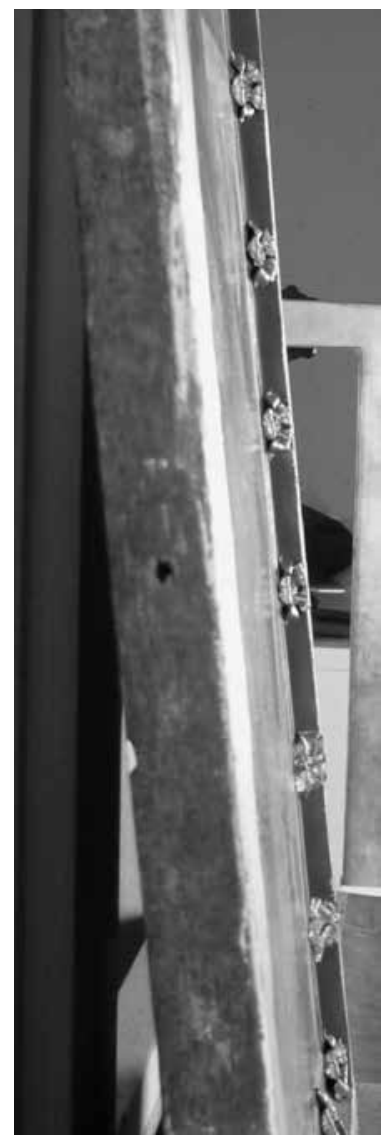

Abb. 16. Linker Rahmen des Gemäldes auf der Abb. 12 (Foto: Museum der bildenden Künste, Leipzig)

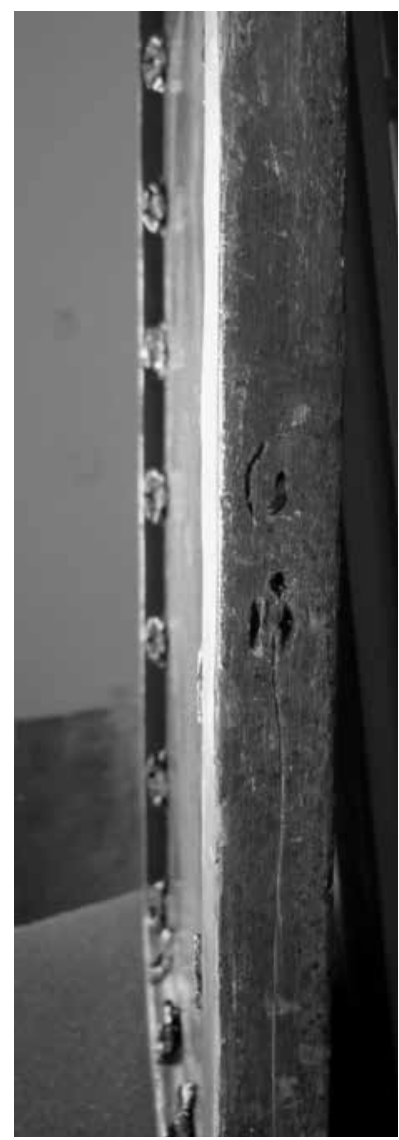

Abb. 17. Rechter Rahmen des Gemäldes auf der Abb. 12 (Foto: Museum der bildenden Künste, Leipzig)

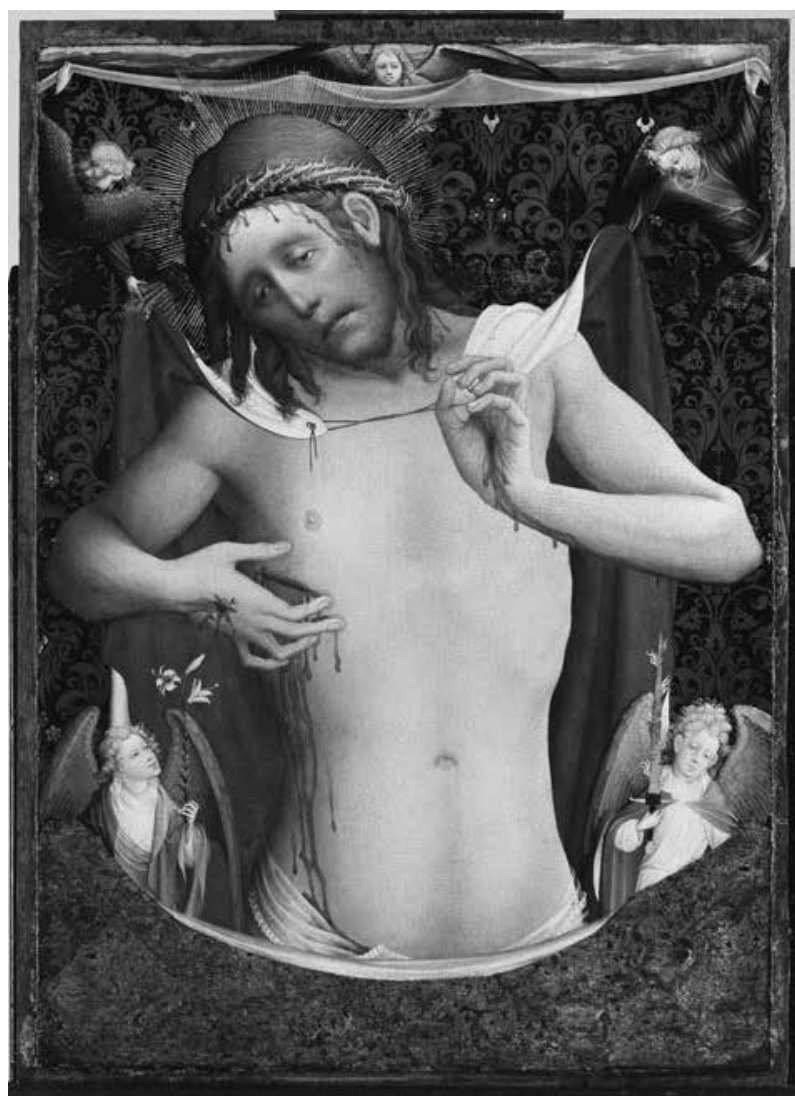

Abb. 18. Sog. Meister Francke: Schmerzensmann, um 1435, 92,5×67 cm. Hamburg, Kunsthalle, Inv.-Nr. 499

(Foto: bpk | Hamburger Kunsthalle | Elke Walford)

den zum Bild entstehen. Der Eindruck von Nähe wird noch dadurch verstärkt, dass der Engel Christus zu der oder dem Betrachtenden hin zu bewegen scheint. Die kleinen Engel werden vom Bildrand sogar etwas überschnitten, wodurch die Darstellung zusätzlich so wirkt, als ob sie sich ganz dicht hinter der Bildoberfläche abspielt. Die Figuren und Gegenstände um Christus überschneiden ihn nach Möglichkeit nicht, deshalb erscheint er der oder dem Betrachtenden am nächsten. Neben dieser kompositorischen Struktur wird noch ein weiteres Detail aufgewandt, um Nähe zu erreichen: Die punzierte Leiste, die unten von der Gestalt des Schmerzensmannes beschnitten wird, rückt ihn - ähnlich wie den Brandenburger Schmerzensmann der oder dem Betrachtenden einmal mehr entgegen. ${ }^{106}$ Nicht zuletzt tragen die geöffneten Augen des Schmerzensmanns zur Intensivierung seiner Wahrnehmung bei: Sie schauen aus dem Bild heraus, suchen das Gegenüber und finden es in der Betrachterin oder dem Betrachter, die oder der sich mit der erbarmungswürdigen Erscheinung Christi auseinandersetzen muss. 
Zur so hergestellten Betrachternähe gesellt sich eine äußerst feine Wiedergabe von Details und Oberflächen, ebenso deren farbliche Differenzierung. Das rosige Inkarnat des großen Engels und dessen blonde, dynamische Locken kontrastieren mit dem leichenblassen Körper des Schmerzensmanns und seinen glatten, braunen, herabhängenden Haaren. Licht und Schatten geben Christus einen dreidimensionalen Körper. Auch die differenzierte Farbgebung der Engelslocken lässt sie trotz ihrer gleichmäßig ornamenthaften Formung plastisch wirken. Das Holz des Kreuzes zeigt eine naturgetreue Maserung. Der Gegenstand ihrer Andacht wird der betrachtenden Person auf eine geradezu realistische Weise dargebracht, ${ }^{107}$ jedoch nicht zum Selbstzweck, sondern als Mittel zur Steigerung des Ausdrucks und um ihr den Einstieg bzw. den Übergang von ihrem Alltag in die in der Andacht vorgestellte himmlische Sphäre zu erleichtern.

Die arma Christi entsprechen keinem realen Maßstab und der Körper Christi ist überlang, während seine Ellenbogen eine unnatürliche Haltung einnehmen. Der Hintergrund entzieht die Darstellung einem realen Ort und erhält damit eine Distanz aufrecht zwischen der Realität der oder des Betrachtenden und jener des abgebildeten Christus. Die blutigen Nägel, die noch im Kreuz stecken, unterstreichen die Zeitlosigkeit der Darstellung, sind nach Michael Camille aber auch eine Betonung der Leiden Christi, da sie wie in Aktion auftreten. ${ }^{108}$ Zusammen mit den anderen Leidenswerkzeugen verweisen sie auf die gesamte Passion Christi und können die Erinnerung an einzelne Leidensstationen hervorrufen. Bildkompositorisch rückt die Figur Christi dem Betrachter so nah wie möglich entgegen. Gleichzeitig ist das Bild nicht nur die Darstellung der Erlösungstat Christi, sondern erinnert seine hostiengleiche Präsentation an die Wiederholung dieses Opfers in der Eucharistie. In den Sakramenten erkennt die oder der Gläubige aber nicht nur einen Erinnerungsakt, sondern auch die Möglichkeit einer Gottesschau.

Die Augen des großen Engels erwecken den Eindruck, als seien sie vom Weinen gerötet. Er gibt der oder dem Betrachtenden eine Haltung vor, die diese oder dieser gegenüber dem leidenden Christus einnehmen soll. Michael Camille hat den Engel als den emotionalen locus für die Identifikation der betrachtenden Person bezeichnet. ${ }^{109}$ Dass Christus gehalten werden muss und sein Körper völlig spannungslos erscheint, verstärkt nur den Eindruck von Hilflosigkeit und Leiden. Camille hat dies in einem anderen Aufsatz als Feminisierung, Miniaturisierung und Infanti- lisierung Christi bezeichnet, die bei der Betrachtung Mitleid hervorrufen würden. ${ }^{110}$ Dadurch würde die Darstellung Christi eine erotische Komponente erhalten und der schwache, verletzliche Christus gleichzeitig verfügbar gemacht. Der Begriff der Feminisierung, den Camille feministischer Literaturtheorie entsprechend mit Klein- bzw. Feinheit verbindet, enthält meines Erachtens keinen Mehrwert für die Deutung eines spätmittelalterlichen Andachtsbildes. Die Miniaturisierung und Infantilisierung, von Camille in Bezug auf wie liturgisches Spielzeug behandelte Christkindpuppen formuliert, gelten dagegen nicht nur für den Leipziger, sondern besonders für den Brandenburger Schmerzensmann - die Miniaturisierung auch für die Hamburger Betnuss. Allerdings wird die Distanz zum eigentlichen Subjekt nicht vergessen, denn trotz aller Nähe, die auch beabsichtigt ist, fehlt nicht der deutliche Bezug auf eine Sphäre, die der oder dem irdischen Betrachtenden nur in der Imagination verfügbar ist. Zudem ist die feine Malerei nicht dazu gemacht, tatsächlich direkt und permanent berührt oder im Sinne einer Puppe manipuliert zu werden.

\section{V.}

Im Folgenden werden die an den drei Andachtsbildern gemachten Beobachtungen in einer Synthese zusammengefasst und noch einmal mit Blick auf die eingangs formulierte These geprüft.

Zunächst liegt bei allen drei Objekten dasselbe Bildthema vor. Der Schmerzensmann ist ein Bildtypus, der in besonderer Weise auf die affektive Frömmigkeit des Spätmittelalters antwortete. In ihrem Zentrum stand Christus, der für die Menschen am Kreuz gestorben war und in seiner Auferstehung über den Tod triumphiert hatte. Der heilsbedürftige Mensch des Spätmittelalters versuchte in der Vergegenwärtigung der Leiden Christi seine Seele zu reinigen. Die Darstellung des Schmerzensmannes half ihm, seinem inneren Auge ein Bild vorzugeben, das die Meditation der Passion erleichterte. Der Schmerzensmann konzentrierte die menschlichen Leiden Christi in einer einzigen Figur und war damit eine sehr dichte Form der heilsgeschichtlichen Vergegenwärtigung. Die ihn in allen drei Bildern umgebenden Passionsinstrumente ermöglichten zusätzlich eine filmsequenzartige Imagination jeder einzelnen Station des Leidenswegs Christi. Dabei blieben sie bewusst ungeordnet und unvollständig, wodurch es der meditativen Leistung der oder des Einzelnen überlassen war, die Werk- 
zeuge zu ergänzen und in die richtige Reihenfolge zu bringen.

Das kleine Format der Andachtsbilder ist von großer Bedeutung. Es bietet „Handlichkeit" 111 im Sinne einer einfachen Handhabung, aber viel mehr noch erfordert es die nahsichtige Betrachtung einer einzelnen Person. ${ }^{112}$ Die Nahsicht wird verstärkt, wenn der Dargestellte als Halbfigur wiedergegeben ist und damit als Partner eines Dialogs wahrgenommen werden kann. Dieses Close-Up besteht hier streng genommen nur beim Leipziger Schmerzensmann. Obwohl der Brandenburger Schmerzensmann in ganzer Figur abgebildet ist, wirkt er dennoch nahe. Seine fehlende Einordnung in den perspektivisch angelegten Raum und seine Plastizität lassen ihn davor schweben. Der Goldhintergrund des Leipziger Schmerzensmannes ist in dieser Wirkung ähnlich. Obwohl Christus plastisch angedeutet ist, wird er nicht in einem entsprechenden Raum verortet. Der Blick wird durch die goldenen Gründe etwas abgefangen und kann nicht in die Ferne schweifen. Im Gegensatz dazu besteht in der Betnuss tatsächlich eine Fernsicht, da die Szenen aufgrund ihrer plastischen Durchgestaltung und ihrer Einlassung in eine runde Form wie ein kleiner Kosmos wirken. Weil sie so klein sind, zwingen sie die betrachtende Person aber, sie so nah wie möglich an ihre Augen heranzuführen.

Die Lenkung des Blicks erfolgt durch Figuren, die den Schmerzensmann umgeben. In der Stickerei sind es Petrus und Paulus, in dem Tafelbild die Engel und in der Betnuss Gregor in der Messszene und Maria in der Kreuzigung, zusätzlich auch die Inschriften. Die Apostel stehen abseits des Schmerzensmanns, wenden sich diesem aber zu. Petrus weist sogar mit der Hand auf ihn. Beide Apostel scheinen einen traurigen Gesichtsausdruck zu haben. Die Engel der Leipziger Tafelmalerei teilen sich mit Christus zwar denselben Bildraum, stehen dabei aber im Hintergrund, entweder durch ihre geringere Größe oder im Fall des großen Engels durch die Position hinter dem Schmerzensmann. Sie halten der oder dem Betrachtenden den Gegenstand der Andacht entgegen und geben durch ihr Mitleiden ein Beispiel richtiger Betrachtung vor. In der Betnuss fordern die Inschriften dazu auf, eine andächtige Haltung einzunehmen. Sie lassen sich aber auch mit jeweils einer Figur in den Szenen verbinden. In der Gregorsmesse bietet der heilige Papst selbst in seiner Rückenansicht eine Identifikationsfigur. Er folgt der Inschrift, welche die Hinwendung des Herzens und der Hände gen Himmel fordert. In der Kreuzigung ist es Christus, dessen Schmerz in der
Inschrift thematisiert und von der Muttergottes exemplarisch nachvollzogen wird. So sind die Figuren um den Schmerzensmann eine Art personifizierter Zeigegestus, gleichzeitig aber auch ein Vorbild andächtigen Verhaltens. Sie erleichtern damit den Einstieg in das Bild und seine richtige Verwendung, d.h. im Sinne der Andacht. Die abgebildeten Emotionen - in der Betnuss aufgrund der Kleinheit der Figuren durch die Inschriften verdeutlicht - sind Anleitung und Identifizierungsmöglichkeit. ${ }^{113}$

Die Fülle an Bilddetails ist ebenfalls als eine Strategie anzusehen, die Betrachterin oder den Betrachter zu beschäftigen und einer allzu schnellen Erfassung des Bildes entgegenzuwirken. Der Blick gleitet über das Bild und wird durch Einzelheiten aufgefangen. Sie sind aber nicht Selbstzweck. Wie mehrfach ausgeführt, handelt es sich gerade im Fall der arma Christi um Bildkürzel, die wiederum für ein vollständiges, vor dem inneren Auge zu entfaltendes Bild stehen.

In den Materialien unterscheiden sich die drei untersuchten Andachtsbilder deutlich voneinander. Allein der halbkugelförmige Raum der Betnuss erzeugt schon den Eindruck eines Mikrokosmos. Die geschnitzten Figuren sind einer tiefenräumlichen Wirkung gemäß gestaffelt angeordnet. Trotz dieser Kleinheit ist jedes Detail plastisch herausgearbeitet und wenn auch nicht sofort zu identifizieren, auf jeden Fall erkennbar. So ist die Dornenkrone Christi sowohl in der Kreuzigung als auch der Gregorsmesse nur durch einen Bogen mit schrägen Einkerbungen angedeutet, für die richtige Zuordnung jedoch völlig ausreichend. Der Körper des Gekreuzigten und des Schmerzensmannes ist durch wenige Ausführungen mit einer Brust und einem Brustkorb versehen. Beide Szenen sind mit vielen Figuren bereichert, die verschiedene Positionen einnehmen und damit eine Mehransichtigkeit bieten, die der Dreidimensionalität entspricht. Das ungefasste Holz kann dabei als ein die Meditation förderndes Merkmal verstanden werden: Es regt zu einer wortwörtlichen Ausmalung der Darstellung mit dem inneren Auge an. ${ }^{114}$ Einen anderen Aspekt des Materials hebt Frits Scholten hervor: Buchsbaumholz wurde im Mittelalter auch als Palmholz bezeichnet und suggerierte damit seine Herkunft aus dem Heiligen Land. Palmholz wiederum soll das Material für das Kreuz Christi geliefert haben, wodurch die fehlende Bemalung mit einer frommen Vorstellung verbunden werden kann. ${ }^{115}$

Das gestickte Andachtsbild arbeitet mit einer farblichen Differenzierung, die an Malerei erinnert, und im Mittelschrein mit einer plastischen Durchformung der 
Gegenstände, die an Schnitzwerke denken lässt. Der weiche Glanz der Seide gibt dem Inkarnat der Figuren einen realistischen Eindruck. Auf Drahtgimpen gewickelte braune Seidenfäden formen sich zu echten Locken auf dem Kopf des Schmerzensmannes. Das in brauner Seide gestickte Kreuz erhält durch den angelegten Silberfaden eine Holzmaserung. Die Metallelemente der Leidenswerkzeuge, der Kopf des Hammers, die Nägel, die Spitze der Lanze usw. sind mit angelegten Silberfäden wiedergegeben und erzeugen dadurch einen Materialrealismus. Dass sie über Leinenwülste gelegt und damit plastisch ausgeführt sind, verstärkt noch ihre realistische Wirkung und lässt sie greifbar erscheinen. Auch die Flussperlen können materialrealistisch aufgefasst werden, etwa an den Mantelsäumen der Apostel und dem Lendentuch Christi. Der vollplastische Schmerzensmann mit seinen herausgearbeiteten Details wie der Nase und dem linken Ohr und seine farblich stimmige Wiedergabe unterstützen die Vergegenwärtigung der Figur.

Das Leipziger Tafelbild gibt durch seinen sehr feinen Farbauftrag die Textur des jeweiligen Gegenstands differenziert wieder. So erzeugt das grünliche Inkarnat des Schmerzensmannes den deutlichen Eindruck eines Leichnams, während die rosigen Gesichter der Engel äußerst lebendig wirken. Das um die Hüfte Christi gelegte Tuch ist transparent und zart gemalt, sodass man an den Schleier Mariens denkt. Das Tuch, mit dem der große Engel Christus berührt, besteht ebenfalls aus einem transparenten Stoff und unterstreicht dadurch die Zartheit und Fragilität des Schmerzensmannes. Der gewählte Bildausschnitt und das Medium ermöglichen die Darstellung feinster Details wie des sich durchzeichnenden Brustkorbs und des Bauchnabels auf dem Körper des Schmerzensmannes. Licht- und Schatteneffekte auf dem Schopf des großen Engels und dem Körper Christi erzeugen Plastizität. Der Einsatz von Gold im Hintergrund verleiht der Darstellung eine zusätzliche Kostbarkeit, ebenso wie die Rosetten auf dem Rahmen des Bildes, die darüber hinaus einen taktilen Reiz bieten.

Aus der beschriebenen Materialbehandlung lässt sich ersehen, dass die drei Andachtsobjekte zwar den Bildinhalt auf verschiedene Weise wiedergeben, sie aber mit ihren jeweils eigenen Mitteln Plastizität und Realismus der abgebildeten Gegenstände und Figuren erzeugen. Die Nähe, welche die Betnuss nicht wie das Tafelbild durch einen feinen Farbauftrag und den nahen Bildausschnitt erzeugen kann, erreicht sie einerseits durch den Realismus vieler Gegenstände, andererseits durch den über die Form der Schnitzerei erzeugten Eindruck eines Mikrokosmos. Die Stickerei kann durch einzelne Fadenführung differenzierte Strukturen wiedergeben, der Malerei nicht unähnlich. Dies geht zwar nicht bis ins kleinste Detail, doch kann sie mit den verwendeten Metallfäden einen Materialrealismus und durch die Erhebung ins Relief Plastizität erreichen.

Aus diesen Beobachtungen lässt sich schließen, dass die drei Bildwerke auf Vergegenwärtigung und Nähe angelegt sind. ${ }^{116}$ Der mehrfach verwendete Begriff des Realismus meint hier nicht eine Form des Erfassens der äußeren Welt als Ausdruck ihrer Durchdringung und die Fähigkeit ihrer Erzeugung durch den Künstler, sondern eine Strategie, das Dargestellte - den Schmerzensmann - als gegenwärtig und nah erscheinen zu lassen. Nähe zu erzeugen muss die logische Konsequenz eines Bildes sein, das bei der oder dem Betrachtenden eine andächtige Stimmung erzeugen will. Doch diese Nähe und die damit einhergehende Möglichkeit der Vergegenwärtigung haben ihre Grenzen, die nicht nur durch die Objekthaftigkeit gesetzt sind, sondern als Teil der Bildstrategie verstanden werden können. Wie in den Einzelanalysen sichtbar, löst die vermeintliche Nähe Impulse des Berührens, Ansehens und Ansprechens - kurz, des Interagierens - aus, die in den Bildwerken selbstverständlich keine Befriedigung finden. Die Nähe schlägt in Distanz um und der Schmerzensmann wird der oder dem Betrachtenden entzogen.

Es ist schon darauf hingewiesen worden, dass das Öffnen eines mehrteiligen Bildes zu einer erhöhten Aufmerksamkeit führt und eine andächtige Stimmung fördert. Gleichzeitig wird damit aber die Schwelle zu einer anderen Wirklichkeit markiert, die nicht überschritten werden kann, weil das im Bild Dargestellte immer Teil dieser anderen Wirklichkeit bleibt.

Alle drei Andachtsbilder arbeiten mit Unvollständigkeiten, d.h. Leerstellen und Unschärfen. Die Leidenswerkzeuge, die in allen drei Objekten auftauchen, sind nie vollständig und müssen gedanklich ergänzt werden. Die Abbildung eines Passionsinstruments und nicht der vollständigen Szene ist an sich schon ein Mittel, eine innere Bilderzeugung auszulösen und sich die einzelnen arma Christi in ihrer ursprünglichen Verwendung vorzustellen. Die Betnuss gewährt trotz ihrer Detailfülle Imaginationsraum. Die oder der Betrachtende stößt nämlich auf Schwierigkeiten bei dem Versuch, die Szenen vollständig zu erfassen, denn viele Elemente sind zu klein oder ihr Blick durch die räumliche Staffelung verstellt. Das Felsengrab im Hintergrund der Kreuzigung ist beispiels- 
weise nur angedeutet, seine Scharfzeichnung findet vor dem inneren Auge statt. Das zur Hälfte überdeckte Gesicht des Engels im Leipziger Schmerzensmann regt ebenfalls zu einer gedanklichen Weiterzeichnung an. Generell erzeugen Überschneidungen immer Flächen, die aufgrund ihrer mangelnden Sichtbarkeit vielmehr gedacht werden müssen.

Verwiesen sei noch einmal auf die eingangs aufgestellte These der in den Andachtsbildern angelegten Dichotomie von Vergegenwärtigung/Nähe und Entziehung/Distanz. Hinter Heilssehnsucht steht Heilsungewissheit, hinter dem Bedürfnis nach Gnadenerwerb die Angst vor Ungnade. In dieses Spannungsfeld tritt die imaginative Leistung des andächtigen Menschen als Möglichkeit einer - zumindest kurzzeitigen Überwindung.

\section{VI.}

Zum Schluss soll das Nachleben von solchen Andachtsbildern wie den vorgestellten in der Neuzeit betrachtet werden. Wie Berndt Hamm konstatiert, verloren die spätmittelalterlichen Medien der Gnadenvermittlung ihren Sinn mit der Reformation, denn: „Wo Gnade und Heil absolut umsonst geschenkt werden und jede aktive Mitwirkung des Menschen ausgeschlossen ist, kann nichts mehr erleichtert werden." 117 Doch war dies möglicherweise nicht der einzige Grund, weshalb die Andachtsbilder außer Gebrauch kamen. Ihre Beschaffenheit und ihre Verwendung bewirkten offensichtlich eine teils schon frühe Ausgliederung aus dem Bereich religiöser Praxis. Wirkten hier die privaten Besitzverhältnisse als Motor oder war das beschriebene Verhältnis zwischen Nähe und Distanz zu unausgewogen, die Nähe am Ende zu groß, um einen dauerhaften Frömmigkeitsimpuls zu erzeugen?

Die Kunstfertigkeit vieler privater Bilder für die Andacht war schon von Beginn an auch Gegenstand ästhetischer Bewunderung, wie vor allem das Beispiel der Miniaturschnitzereien aus Buchsbaum zeigt. ${ }^{118}$ Man besaß sie nicht nur aus religionspraktischen Gründen, sondern demonstrierte durch ihren Erwerb auch Wohlstand. ${ }^{119}$ Die fürstlichen Inventare zeigen einen reichen Besitz an Goldschmiedearbeiten, illuminierten Büchern, Elfenbeinarbeiten und Tafelbildern. Die Prunkentfaltung geschah in repräsentativer und den Status sichernder Absicht gegenüber anderen Höfen und dem Adel. ${ }^{120}$ Die Höfe schätzten die Objekte vor allem wegen ihrer kunstfertigen Bearbeitung teurer Materialien und verschenkten sie in dip- lomatischer Absicht untereinander. ${ }^{121}$ Hans Belting schreibt dazu: „Man sammelte und tauschte Preziosen, die zwar als Andachtsbilder und Gebetbücher legitimiert waren, aber ihre eigentliche Funktion im Warenwert und Repräsentationszweck fanden." 122 Die schiere Menge an Gegenständen machte ihren alltäglichen Gebrauch unwahrscheinlich, auch waren ihre häufig kostbaren Materialien nicht dafür geeignet. ${ }^{123}$ Hinter einer solchen Profanierung des religiösen Bildes stand auch ein mit der Distanzverringerung einhergehender Verlust der sakralen Aura des Bildes. Die Distanz zu einem Bild hing unter anderem mit seiner Zugänglichkeit zusammen. Ein privates Bild konnte jederzeit betrachtet werden, war demnach immer verfügbar - anders als ein Altar- oder Gnadenbild, dessen Zugang von der Kirche eingeschränkt wurde. ${ }^{124}$ Ein Andachtsbild innerhalb eines größeren Privatbesitzes konnte demnach nicht in demselben Maße herausgehoben sein. Hervorheben konnte es sich in diesem Fall nur durch eine besondere Gestaltung und einen erhöhten Materialaufwand. Auf diese Weise verstärkte sich aber die Wertschätzung der materiellen und handwerklichen Qualitäten eines Andachtsbildes. ${ }^{125}$ Diese wiederum unterlief den ursprünglichen Sinn der Erzeugung einer andächtigen Stimmung. So finden sich die eigentlich zur privaten Meditation hergestellten Betnüsse schon früh in fürstlichen Schatzkammerinventaren wieder und werden dort neben anderen kunstfertigen Gegenständen aufgeführt. ${ }^{126}$ Die die Aufmerksamkeit fesselnden, nur wenige Millimeter großen beweglichen Elemente - wie der lose Mauerring am Stall einer Geburts- und Anbetungsszene ${ }^{127}$ - konnten dabei zusätzlich die „toys for the soul“128 zu toys for the eyes werden lassen und damit andächtiges Spiel in eine Spielerei verwandeln.

Es scheint, dass die Strategie von Vergegenwärtigung/Nähe und Entziehung/Distanz nur wirkte, solange es ein meditatives Fernziel, die Gottesnähe, gab und die innere Verfasstheit der betrachtenden Person ganz darauf ausgerichtet war. Schon Hieronymus Emser (1478-1527) warnte vor allzu kunstvollen Bildern, die sich der Betrachtung der Heiligen selbst und ihrer Verinnerlichung entzogen. ${ }^{129}$ Dazu sei ein Blick auf die von Simone Husemann behandelte Gruppe der Andachtspreziosen geworfen, die ein gutes Vergleichsbeispiel bietet. Kleinformatige Medaillons und Reliefs aus Perlmutt und Email dienten ursprünglich einem religiösen Bedürfnis. ${ }^{130}$ Dass aus einem „devotional jewel"131 jedoch ein bloßes Schmuckstück werden konnte, scheint vorstellbar. Hans Belting entnimmt den fürstlichen Inventaren sogar, dass zwischen Andachts- 
bild und Schmuckstück nicht unterschieden wurde, sondern für beide gleichermaßen die Bezeichnung joyau Verwendung fand. ${ }^{132}$ Ihr Gebrauch zur Andacht trat demzufolge in den Hintergrund zugunsten der Bewun- derung ihres materiellen Werts und ihrer künstlerischen Virtuosität. Zugleich konnte eine solche Betrachtungsweise aber auch den Fortbestand von Andachtsbildern - nun ohne Andachtsfunktion - sichern.

\section{ANMERKUNGEN}

${ }^{1}$ Der Aufsatz basiert auf einer Magisterarbeit, die 2011 an der Universität Leipzig eingereicht wurde. Es handelt sich um eine gekürzte, ergänzte und überarbeitete Fassung.

${ }^{2}$ LimBECK, Sven: Speciosus forma prae filiis hominum. Der schöne, hässliche und nackte Körper Christi in der Frömmigkeit vom Spätmittelalter zu Renaissance, in Wie fromm waren die Humanisten?, hrsg. von Hamm, Berndt - Kaufmann, Thomas, Wiesbaden: Harrassowitz, 2016. 65-97, hier 82-83.

${ }^{3}$ LiMBECK 2016 (vgl. Anm. 2), 83.

${ }^{4}$ Limbeck 2016 (vgl. Anm. 2), 82 zählt den Text zu „den am weitesten verbreiteten und rezipierten Passionsbetrachtungen im späten Mittelalter und in der frühen Neuzeit" und verweist auf seinen Eingang als Kirchenlied.

${ }^{5}$ Magnus, Rosemarie: Die Christusgestalt im Passionsspiel des deutschen Mittelalters (Dissertation), Universität Frankfurt M., 1965. 163. Originaltext: „Tu autem si ex his fructum sumere cupis, ita presentem te exhibeas his que per Dominum Iesum dicta et facta narrantur ac si tuis auribus audires et oculis ea uideres, toto mentis affectu dilligenter, delectabiliter et morose, omnibus aliis curis et sollicitudinibus tuns omnissis." Johannis de Caulibus: Meditaciones Vite Christi olim S. Bonaventuro attributae (Corpus Christianorum, Continuatio Mediaevalis. Bd. 153), hrsg. von StallINGS-TANnEY, Mary, Turnhout: Brepols 1997. 10 (Prologus), Z. 103-107.

${ }^{6}$ Hamm, Berndt: Die Medialität der nahen Gnade im späten Mittelalter, in Medialität des Heils im späten Mittelalter, hrsg. von Dauven-VAn KNIPPEnBerg, Carla - HeRberichs, Cornelia - Kiening, Christian, Zürich: Chronos, 2009. 21-59, hier 21.

${ }^{7}$ Hamm 2009, (vgl. Anm. 6) 43.

${ }^{8}$ Dies sollte nicht unbedingt negativ verstanden werden. Wie Bruno Boerner demonstriert, galt im religiösen Diskurs des Hochmittelalters ein emotionaler und sinnlicher Zugang zum Göttlichen zwar noch als Erleichterung für Laien, doch wurde deren theologische simplicitas im Spätmittelalter zunehmend positiv konnotiert und einer intellektuellen Frömmigkeit teils vorgezogen, z.B. in der Bewegung der devotio moderna. BOERNER, Bruno: Bildwirkungen. Die kommunikative Funktion mittelalterlicher Skulpturen, Berlin: Reimer, 2008. $112-113$

${ }^{9}$ Hamm 2009, (vgl. Anm. 6) 43-46 und Abb. 10. Es handelt sich um einen Einblattholzschnitt auf Papier aus dem süddeutschen Raum, um 1480, 353×252 cm, in der Staatlichen Graphischen Sammlung in München, Inv.-Nr. 118.124.

${ }^{10}$ TRIPPS, Johannes: Ein Crucifix, dem ausz den funff Wunden rotter Wein sprang. Die Inszenierung von Christusfiguren in Spätgotik und Frührenaissance, in Das Bild Gottes in Judentum, Christentum und Islam. Vom Alten Testament bis zum Karikaturenstreit, hrsg. von LeUSCHNER, Eckhard, Petersberg: Michael Imhof, 2009. 117-127, hier 119-120, Abb. 2-4.
${ }^{11}$ "Numquam promittas tibi securitatem in hac vita, quamvis bonus videaris coenobita, aut devotus eremita." Thomas à KempIs: De imitatione Christi libri quatuor, hrsg. und übers. von Weigl, Johann Baptist, Sulzbach: Seidel, 1837. 74 (lib. I, c. 20, 3).

${ }^{12}$ Eine Trennung der Gattungen entspricht auch nicht mittelalterlicher Wahrnehmung, wie die wenigen in diesem Kontext überlieferten Quellen implizieren: BOERNER 2008 (vgl. Anm. 8), 13.

${ }^{13}$ SCHRADE, Hubert: Beiträge zur Erklärung des Schmerzensmannbildes, in Deutschkundliches. Friedrich Panzer zum 60. Geburtstage überreicht von Heidelberger Fachgenossen, hrsg. von TESKE, Hans, Heidelberg: Winter 1930. 164-182, hier 164 .

${ }^{14}$ Ein besonders treffendes Beispiel findet sich bei Boerner 2008 (vgl. Anm. 8), 124-125. Ein Wandbild in der Abteikirche St. Peter und Paul in Wissembourg (Luxemburg) stellt den Schmerzensmann und seine Passionswerkzeuge mit folgenden Versen dar: „Dis ist die forme des heiligen / speres das unserm Herren / durch sin site wart / gestochen / dis han ich gelitten durch dich / alle meine wunden verswerst / du mir. huet und alle stunde.“ - „Dies ist die Form des heiligen Speers, der unserem Herrn durch seine Seite gestochen wurde. Dies habe ich durch dich gelitten. Alle meine Wunden vergrößerst du mir. Heute und zu jeder Stunde." Boerner selbst schreibt dazu: „Der Appell des Schmerzensmannes in Weißenburg ist also eine Anklage, die den Betrachter dazu stimuliert, über seine Sündhaftigkeit zu reflektieren."

${ }^{15}$ LenTES, Thomas: Inneres Auge, äußerlicher Blick und heilige Schau. Ein Diskussionsbeitrag zur visuellen Praxis in Frömmigkeit und Moraldidaxe des späten Mittelalters, in Frömmigkeit im Mittelalter. Politisch-soziale Kontexte, visuelle Praxis, körperliche Ausdrucksformen, hrsg. von SCHREINER, Klaus, München: Fink, 2002. 179-220, hier 187-188.

${ }^{16}$ Literatur zum Andachtsbild und Schmerzensmann (in Auswahl): PANOFSKY, Erwin: Imago Pietatis. Ein Beitrag zur Typengeschichte des Schmerzensmanns und der Maria Mediatrix, in Festschrift für Max J. Friedländer zum 60. Geburtstage, Leipzig: Seemann, 1927. 261-308; SPAMER, Adolf: Das kleine Andachtsbild vom XIV. bis zum XX. Jahrhundert, München: Bruckmann, 1930; Osten, Gert von der: Der Schmerzensmann. Typengeschichte eines deutschen Andachtsbildwerkes von 1300 bis 1600, Leipzig: Spamer, 1933; Mersmann, Wiltrud: Der Schmerzensmann, Düsseldorf: L. Schwann, 1952; BeLTING, Hans: Das Bild und sein Publikum im Mittelalter, Berlin: Gebr. Mann, 1981; The Art of Devotion in the Late Middle Ages in Europe, Ausstellungskatalog, hrsg. von Os, Hendrik van, Rijksmuseum Amsterdam, London: Merrell Holberton, 1994; The Broken Body. Passion devotion in late medieval culture, hrsg. von Macdonald, Alasdair - RidDERBos, Herman, Groningen: Forsten, 1998; Spiegel der Seligkeit. Privates Bild und Frömmigkeit im Spätmittelalter, Ausstellungskatalog, 
hrsg. von GrossmanN, Ulrich, Germanisches Nationalmuseum Nürnberg: Verlag des Germanischen Nationalmuseums, 2000; SCHADE, Karl: Andachtsbild. Die Geschichte eines kunsthistorischen Begriffs, Weimar: VDG, 1996; SANDER, Jochen et al.: KultBild. Das Altar- und Andachtsbild von Duccio bis Perugino, Ausstellungskatalog, Städel-Museum Frankfurt M., Petersberg: Michael Imhof, 2006; New perspectives on the Man of Sorrows, hrsg. von Puglisi, Catherine - BARCHAM, William, Kalamazoo: Medieval Inst. Publ., 2013. Die Differenzierung nach Schmerzensmanntypen erscheint aus der Perspektive der Untersuchung bedingt zweckmäßig und wird deshalb unterlassen. Verwiesen sei auf: ZimmermanN, Andrea: Jesus Christus als Schmerzensmann in hoch- und spätmittelalterlichen Darstellungen der bildenden Kunst (Dissertation), Universität Halle, 1997.

${ }^{17}$ Sog. Werkstatt des Adam Dircksz: Betnuss mit Kreuzigung und Gregorsmesse. Nordniederlande, 1500-1530. Buchsbaum geschnitzt, Dm. 4,1 cm. Hamburg, Museum für Kunst und Gewerbe, Inv.-Nr. 1878.134. Literatur: BRINCKMANN, Justus: Hamburgisches Museum für Kunst und Gewerbe, Hamburg: Seemann, 1894. 718; DingELSTEDT, Kurt: Betnuß, in Reallexikon zur deutschen Kunstgeschichte, Bd. 2. 1938. Sp. 371-377, hier Sp. 375. RDK Labor: http://www.rdklabor. de/w/?oldid=89325 (26. Juni 2018); LEEUWENBERG, Jaap: De Gebedsnoot von Eewert Jansz van Bleiswick en andere wirken van Adam Dirksz, in Miscellanea Jozef Duverger. Bijdragen tot de kunstgeschiedenis der Nederlanden, Bd. 2, Gent: Vereniging voor de Geschiedenis der Textielkunsten, 1968. 614-624, hier 620-621; Museum für Kunst und Gewerbe Hamburg. Handbuch, hrsg. von SALDERN, Axel von, München: Prestel, 1980. 73, Kat. 135; Romanelli, Susan: South Netherlandish boxwood devotional sculpture 1475-1530 (Dissertation), University of Columbia, New York, 1992. 291-292, Kat. 33; Spiegel der Seligkeit 2000 (vgl. Anm. 16). 284-285, Kat. 109; LenTES, Thomas: Bildertotale des Heils. Himmlischer Rosenkranz und Gregorsmesse, in Der Rosenkranz. Andacht, Geschichte, Kunst, Ausstellungskatalog, hrsg. von FreI, Urs-Beat - BüHLER, Fredy, Museum Bruder Klaus Sachseln, Bern: Benteli, 2003. 68-87, hier 87, Abb. 16.

${ }_{18}$ Der Begriff Betnuss (prayer nut, gebedsnoot, noix de chapelet) lässt sich in Quellen des 16. Jahrhunderts nachweisen, wurde aber eher selten verwendet. Gebräuchlicher war die Bezeichnung appel (Apfel); s. ScHolten, Frits: The Boxwood carvers of the late gothic Netherlands, in Small wonders. Late-Gothic boxwood micro-carvings from the Low Countries, Ausstellungskatalog, hrsg. von ScHOLTEN, Frits, Rijksmuseum Amsterdam, Amsterdam: Rijksmuseum Publ. Dep., 2017. 12-80, hier 15-20. Nach dem Ausstellungskatalog richten sich auch die Datierungsvorschläge für alle genannten Buchsbaumschnitzereien, die auf den Internetseiten der besitzenden Museen teils mit 1500-1530 oder frühes 16 . Jahrhundert angegeben werden.

${ }^{19}$ Literatur zur Gruppe der Betnüsse bzw. Miniaturschnitzereien aus Buchsbaum: DingELsTEDT 1948 (vgl. Anm. 17); LeEUWENBERG 1968 (vgl. Anm. 17); Romanelli 1992 (vgl. Anm. 16); Scholten, Frits - Falkenburg, Reindert: A Sense of Heaven. 16th century boxwood carvings for private devotion. Ausstellungskatalog Henry-Moor-Institute Leeds, Leeds: Henry Moore Sculpture Trust, 1999; SCHOlten, Frits: Joost van Cranevelt's prayer nut, Simiolus 36. 2012. 123-141; SCHOlten, Frits: Handzaam verzamelen, Amsterdam: Vrije Universiteit, 2011; WeTTER, Evelin: Zwei spätmittelalterliche
Betnüsse aus den südlichen Niederlanden, Riggisberg: AbeggStiftung, 2011; Prayer nuts, private devotion, and early modern art collection, hrsg. von WeTtER, Evelin - SCHOLTEN, Frits, Riggisberg: Abegg-Stiftung, 2017; Small wonders 2017 (vgl. Anm. 18).

${ }^{20}$ Die Werkstatt wird in Ermangelung sicherer Belege mit dem Namen Adam Dircksz bezeichnet. Dies geht auf eine Betnuss mit der Inschrift „Adam Theodrici me fecit“ zurück, das einzige Objekt mit einer Künstlersignatur - wenn es sich um eine solche handelt. Die Entdeckung geht zurück auf LeEUWEnBerg 1968 (vgl. Anm. 17), 618. Zuletzt dazu: SCHOLten 2017 (vgl. Anm. 18), 24-35.

${ }^{21}$ Siehe z.B. Small wonders 2017 (vgl. Anm. 18), 317-319, Kat. 45; 397, Kat. 50; 413, Kat. 58.

22 Beispiele: Meister der Maria von Burgund: Kreuzannagelung, Stundenbuch der Maria von Burgund. Gent, um 1475-1480. Tempera und Blattgold auf Pergament, $22,5 \times 16,3 \mathrm{~cm}$. Wien, Österreichische Nationalbibliothek, Cod. Vindobonensis 1857, fol. 43v; Abb. bei Wetter 2011 (vgl. Anm. 19), 36, Abb. 24; Jacob Cornelisz van Oostsanen (Werkstatt): Porträt des Jan Gerritsz van Egmond van de Nijenburg. Amsterdam, um 1518. Öl auf Leinwand, $42,4 \times 32,8 \mathrm{~cm}$. Amsterdam, Rijksmuseum, Inv.-Nr. SK-A3838; Abb. in Early Netherlandish Paintings, hrsg. von FILEDT Kok, Jan Pieter, Online Collection Catalogue, Amsterdam 2010: hdl.handle.net/10934/RM0001.COLLECT.8171 (26. Juni 2018); Jan van Scorel: Porträt einer Stifterin (rechter Flügel eines Triptychons). Utrecht, um 1535. Öl auf Leinwand, 98,5×28,5 cm. Utrecht. Museum Catharijneconvent, Inv.-Nr. ABM s95; Abb. in Small wonders 2017 (vgl. Anm. 18), 245-246.

${ }^{23}$ Heinz, Andreas: Der Rosenkranz vor dem Hintergrund seiner Entstehungsgeschichte, in Edelsteine, Himmelsschnüre. Rosenkränze und Gebetsketten. Ausstellungskatalog, Dommuseum Salzburg, Bd. 1, hrsg. von Keller, Peter - Neuhardt, Johannes, Salzburg: Dommuseum zu Salzburg, 2008. 21-32, hier 26 .

${ }^{24}$ SANDER, Hans-Joachim: Eine Berührung in der Not und im Segen des Gebets, in Edelsteine, Himmelsschnüre 2008 (vgl. Anm. 23), 15-50, hier 15-16.

${ }^{25}$ Christlieb, Björn: Heilssuche, Andacht und Politik: Formen stadtbürgerlicher Laienfrömmigkeit, in Spätmittelalter am Oberrhein. Alltag, Handwerk und Handel (1350-1525), hrsg. von LOREnZ, Sönke - ZoTz, Thomas, Badisches Landesmuseum Karlsruhe, Stuttgart: Thorbecke, 2001. 453463, hier 456

${ }^{26}$ Vgl. z.B. Altarretabel mit Passionsszenen. Brüssel, um 1520. Holz gefasst und vergoldet, $100 \times 94 \mathrm{~cm}$. Köln, Museum Schnütgen, Inv.-Nr. A 1095; Abb. in Museum Schnütgen, Wege durch die Sammlung, Kunst um 1500: http://www.museum-schnuetgen.de/Wege-durch-die-Sammlung?kat=14 (26. Juni 2018).

${ }^{27} \mathrm{Vgl}$. dazu Anm. 36.

${ }^{28}$ Literatur zur Gregorsmesse (in Auswahl): ENDRES, Joseph Anton: Die Darstellung der Gregorsmesse im Mittelalter, Zeitschrift für christliche Kunst 30. 1917. 146-156; Bertelli, Carlo: The Image of Pity in Santa Croce in Gerusalemme, in Essays in the history of art presented to Rudolf Wittkower, hrsg. von FRASER, Douglas - HIBBARD, Howard London: Phaidon, 1967. 40-55; MEIER, Esther: Die Gregorsmesse. Funktionen eines spätmittelalterlichen Bildtypus, KölnWeimar-Wien: Böhlau, 2006. 
${ }^{29}$ Eine Kurzfassung findet sich bei HECHT, Christian: Schmerzensmann und Gregorsmesse, in Trotz Natur und Augenschein. Eucharistie - Wandlung und Weltsicht, Ausstellungskatalog, hrsg. von SuRMANN, Ulrike - SCHRÖER, Johannes, Kolumba Kunstmuseum des Erzbistums Köln, Köln: Greven, 2013. 277-282, hier 280 und 298.

${ }^{30}$ Ein Stich von Israhel van Meckenem überliefert die Mosaikikone. Die dreizeilige Bildunterschrift erklärt, dass der Stich eine getreue Kopie der imago pietatis in Santa Croce ist, die Papst Gregor nach seiner Vision anfertigen ließ: Der Schmerzensmann, um 1495. Kupferstich, 16,6×11 cm. Berlin, Staatliche Museen, Kupferstichkabinett, Inv.-Nr. 943-1; Abb. in HeCHT 2013 (vgl. Anm. 29), 299.

${ }^{31}$ Lamentationes 1,12: ,attendite et videte si est dolor sicut dolor meus“; Originaltext der Inschrift: „Attendite et videte si est dolor sicut dolor meus Jhe primo"; BRINCKMANN 1894 (vgl. Anm. 17), 728; Spiegel der Seligkeit 2000 (vgl. Anm. 16), 284-285 (Kat. 109: CurTius, Andreas).

32 SOLTÉsz, Elisabeth: Biblia Pauperum. Faksimileausgabe des vierzigblättrigen Armenbibel-Blockbuches in der Bibliothek der Erzdiözese Esztergom, Hanau M.: Dausien, 1967. 26, Druck XXI.

${ }^{33}$ Ludolphus de Saxonia: Vita Jesu Christi e quatuor Evangeliis et scriptoribus orthodoxis concinnata, hrsg. von BOLARD, Clovis - Rigollot, Louis Marie - CARnANDET, Jean Baptiste, Paris-Rom: Palmé, 1865. 653 (pars 2, c. LXIII).

${ }^{34}$ Weigl 1837 (vgl. Anm. 11), 180-196 (lib. 2, c. XII).

35 BrandsCheidt, Renate: Das Buch der Klagelieder, Düsseldorf: Patmos, 1988. 157.

36 SCHREINER, Klaus: Maria. Jungfrau, Mutter, Herrscherin, München-Wien: Hanser, 1994. 105. In Passionsspielen wurde der Vers aus den Klageliedern zuweilen auch der unter dem Kreuz trauernden Maria selbst in den Mund gelegt. Siehe dazu: Young, Karl: The Drama of the Medieval Church, Oxford: Clarendon, 1933. 500-511.

37 Lamentationes 3,41: „levemus corda nostra cum manibus ad Dominum in caelos"; Originaltext der Inschrift: „levemus corda nostra cu manibus ad dum in celos Jhe tertio"; BRINCKMANN 1894 (vgl. Anm. 17), 718.

38 Sog. Werkstatt des Adam Dircksz: Betnuss mit Kreuztragung (oben) und Kreuzigung (unten). Nordniederlande, 1500-1530. Buchsbaum geschnitzt, 5,5×4,6 cm (geschlossen). London, British Museum, Inv.-Nr. WB.235; Abb. in British Museum Collection Online: https://www.britishmuseum. org/research/collection_online/collection_object_details.aspx ?objectId=32482 \&partId=1\&images=true (26. Juni 2018).

39 Sog. Werkstatt des Adam Dircksz: Betnuss mit Anbetung der drei Magier (oben) und Kreuzigung (unten) - Betnuss mit Kreuzigung (oben) und Christus vor Pilatus (unten). Nordniederlande, 1500-1530. Buchsbaum geschnitzt, 5,8 $\times 5,5 \mathrm{~cm}$ - 6,4×6,1 cm (geschlossen). New York, Metropolitan Museum of Art, Inv.-Nr. 17.190.475 - 17.190.474a; Abb. in Small wonders 2017 (vgl. Anm. 18), 215 und 416 (Kat. 26), 217 und 416 (Kat. 27).

40 Sog. Werkstatt des Adam Dircksz: Diptychon mit Geburt Christi und Gregorsmesse. Nordniederlande, 1500-1530. Buchsbaum geschnitzt, $8,3 \times 4,5 \mathrm{~cm}$ (geschlossen). New York, Metropolitan Museum of Art, Inv.-Nr. 17.190.476.

${ }^{41}$ Für die Inschriften siehe: Small wonders 2017 (vgl. Anm. 18), 624, Kat. 46.

42 Lentes 2003 (vgl. Anm. 17), 83.
${ }^{43}$ Siehe dazu Timmermann, Achim: Real Presence. Sacrament houses und the body of Christ, c. 1270-1600, Turnhout: Brepols, 2009. 1-7.

${ }^{44}$ Meister IAM von Zwolle: Gregorsmesse. Nordniederlande, drittes Drittel 15. Jh. Kupferstich, 32,3×22,4 cm (Blatt). München, Staatliche Graphische Sammlung, Inv.-Nr. 1909:374 D. Siehe dazu: LeHRS, Max: Geschichte und kritischer Katalog des deutschen, niederländischen und französischen Kupferstichs im 15. Jahrhundert, Bd. 7, Wien: Gesell. für vervielfältigende Kunst, 1930. 210-211, Kat. 21 (Textbd.). Taf. 197, Nr. 486 (Tafelbd.). Zum Künstler siehe auch: FILEDT KoK, Jan: Master IAM of Zwolle, in Dictionary of Art, Bd. 20, Oxford: Grove, 1998. 799. Kok äußert die Vermutung, dass seine Kupferstiche als Vorlagen für Reliefs verwendet wurden.

${ }^{45}$ Sog. Werkstatt des Adam Dircksz: Anhänger mit Gregorsmesse (Vorderseite), Verkündigung an Maria und zwei Betenden mit Rosenkranz vor Marienfigur (Rückseite). Nordniederlande, 1500-1530. Buchsbaum geschnitzt, 6,4×4 cm. London, British Museum, Inv.-Nr. WB.241. Für das New Yorker Diptychon siehe Anm. 39.

${ }^{46}$ Wetter 2011 (vgl. Anm. 19), 71.

${ }^{47}$ Nicolaisen, Jan: Einige Beobachtungen zur Privatisierung des gedruckten Bildes im 17. Jahrhundert, in Spiegel der Seligkeit 2000 (vgl. Anm. 16), 84-96.

${ }^{48}$ Nicolaisen 2000 (vgl. Anm. 47), 87.

${ }^{49}$ Scholten 1999 (vgl. Anm. 19), 19; Husemann, Simone: Pretiosen persönlicher Andacht. Bild und Materialsprache spätmittelalterlicher Reliquienkapseln, Weimar: VDG, 1999. 101.

${ }^{50}$ Rimmele, Marius: (Ver-)Führung durch Scharniere. Zur Instrumentalisierung kleinformatiger Klappbilder in der Passionsmeditation, in DAUVEN-VAN KNIPPENBERG-HerbeRICHS-KIENING 2009 (vgl. Anm. 6). 111-130, hier 116-117.

${ }^{51}$ Ein entsprechender Text befindet sich am unteren Rand des besprochenen Kupferstichs des Meisters IAM von Zwolle; siehe LeHRS 1930 (vgl. Anm. 44), 211 (Textbd.).

52 Meier 2006 (vgl. Anm. 28), 176-182.

${ }^{53}$ LeNTES 2003 (vgl. Anm. 17), 70 und 81. Lentes behandelt unter anderem Einblattholzschnitte des so genannten Himmlischen Rosenkranzes. Die Abbildung der himmlischen Gemeinschaft wird außerhalb des kreisförmig angeordneten Rosenkranzes noch von verschiedenen Gnadenbildern, darunter auch der Gregorsmesse, unterstützt. Gehen die einzelnen Darstellungen allein schon auf gnadenreiche Bilder zurück, werden sie in der Zusammenschau multipliziert.

${ }^{54}$ BERNS, Jörg Jochen: Rosarium und Bilddrift. Zur präcinematischen Bedeutung des Rosenkranzgebets, in Der Rosenkranz 2003 (vgl. Anm. 17), 303-320, hier 304 und 309. Berns vergleicht diese drei Ebenen des Rosenkranzes mit Bändern, die einen inneren Film erzeugen. Die Ergänzung um Bilder, die eigentlich nur imaginiert werden sollen, stellt für ihn ebenfalls eine für die Handhabung nicht notwendige Strategie dar.

${ }^{55}$ Für die Betnuss mit Szenen aus dem Leben der Maria Magdalena nach Lucas van Leyden ist eine 20 Seiten umfassende Beschreibung des Adligen Joost van Cranevelt von 1633 überliefert: SCHOLTEN 2012 (vgl. Anm. 19), 123-124. Scholten beschreibt den Betrachtungsprozess bei Betnüssen und anderen Miniaturschnitzereien auch als „hyperconcentration", der bewirkt, dass die investierte Zeit als wesentlich kürzer wahrgenommen wird: ScHOLTEN, Frits: Scale, prayer 
and play, in Small wonders 2017 (vgl. Anm. 18), 171-210, hier 182-185.

${ }^{56}$ Ein besonders erstaunliches Detail, das den Impuls, die Schnitzereien anzufassen, verstärkte, sind bewegliche Mauerringe in einigen Exemplaren: SCHOLtEn 2017 (vgl. Anm. 18), 63 und Abb. 54.

${ }^{57}$ Zur spirituellen Komponente des sogenannten Turmblicks siehe: SCHOLTEN 2017 (vgl. Anm. 55), 174-177.

${ }^{58}$ FALKENBURG, Reindert: Toys for the soul. Prayer-nuts and pomanders in late medieval devotion, in A Sense of Heaven 1999 (vgl. Anm. 19), 32-44, hier 40. Siehe auch GANZ, David: Weder eins noch zwei. Jan van Eycks Madonna in der Kirche und die Scharnierlogik spätmittelalterlicher Diptychen, in Das Bild im Plural, hrsg. von Ganz, David Thürlemann, Felix, Berlin: Reimer 2010. 41-67, hier 49. Ganz bezieht die ergänzende Imagination von Bildern durch den Betrachter auf die nur unscharf wahrnehmbaren Bilder im Kircheninneren von van Eycks Madonna in der Kirche.

59 Triptychon mit Schmerzensmann zwischen zwei Aposteln. Nürnberg (?), 1485-1507. Reliefstickerei mit Seide, Gold, Silber und Perlen, $25 \times 22,1 \mathrm{~cm}$ (Kasten), $25 \times 11,2 \mathrm{~cm}$ (rechter Flügel), $25 \times 10,5$ (linker Flügel). Brandenburg, Domschatz, Inv.-Nr. B 7 (Kasten) und B 6 (Flügel). Literatur: BerGAU, Rudolf: Inventar der Bau- und Kunst-Denkmäler in der Provinz Brandenburg, Berlin: Vossische Buchhandlung, 1885. 194; EICHHOLz, Paul: Die Kunstdenkmäler von Dom und Stadt Brandenburg, Berlin, 1912. 317; Die Bau- und Kunstdenkmale in der DDR. Bezirk Potsdam, bearb. von DRESCHER, Horst et al., Berlin: Henschel, 1978. 78; Liturgische Gewänder und andere Paramente im Dom zu Brandenburg, Bestandskatalog, hrsg. von ReiHlen, Helmut, red. von JeHLEN, Manfred - WetTer, Evelin, Domschatz Brandenburg, Regensburg: Schnell und Steiner, 2005. 266-268 (Kat. 29: JeITNER, Christa - WeTter, Evelin).

${ }^{60} \mathrm{Vgl}$. z.B. Liturgische Gewänder und andere Paramente 2005 (vgl. Anm. 59), 274-275 (Kat. 32: JeITnER, Christa WETTER, Evelin).

${ }^{61}$ Camille, Michael: Die Kunst der Gotik. Höfe, Klöster, Kathedralen, Köln: DuMont 1996. 120; DinZElBACHER, Peter: Himmel, Hölle, Heilige. Visionen und Kunst im Mittelalter, Darmstadt: Primus, 2002. 298.

62 Die losen schwarzen Fäden auf dem Säulenkapitell lassen vermuten, dass sich darauf noch der Hahn als Symbol der Verleugnung Petri befunden hat.

${ }^{63}$ Eine kolorierte Druckgraphik zeigt ähnlich ausgeführte Wunden um eine Abbildung des Schmerzensmannes mit Leidenswerkzeugen: Psalter und Rosenkranz der Muttergottes sowie andere Andachtstexte. England, um 1480/1490. Kolorierter Holzschnitt, 12,5 cm $\times 8,9 \mathrm{~cm}$. London, British Library, Ms. Egerton 1821, fol. 8v; Abb. und Daten in: British Library, Catalogue of Illuminated Manuscripts: https:// www.bl.uk/catalogues/illuminatedmanuscripts/record. asp?MSID=8389 (26. Juni 2018).

${ }^{64}$ Siehe z.B. FIRCKS, Juliane von: Serienproduktion im Medium mittelalterlicher Stickerei - Holzschnitte als Vorlagenmaterial für eine Gruppe mittelrheinischer Kaselkreuze des 15. Jahrhunderts, in Reiche Bilder. Aspekte zur Produktion und Funktion von Stickereien im Spätmittelalter, hrsg. von Bergemann, Uta-Christiane, Regensburg: Schnell und Steiner, 2010. 65-82.

65 SCHADE, Karl: Ad excitandum devotionis affectum. Kleine Triptychen in der altniederländischen Malerei, Weimar: VDG, 2001. 78-79; Rimmele, Marius: Das Triptychon als Metapher,
Körper und Ort. Semantisierungen eines Bildträgers, München Fink, 2010. 73

${ }^{66}$ Diptychon mit Schmerzensmann und Schmerzensmutter. Ungarisch, um 1500. Holz, Reliefstickerei mit Seide, Gold, Silber und Perlen, 20,7×18,5 cm. Esztergom, Fószékesegyházi kincstár [Domschatzkammer], Inv.-Nr. 1964.314.1,2. Zur ungarischen Andachtsstickerei in Gestalt eines Diptychons siehe: CSERNYÁnsZKY, Mária: Az esztergomi fốszékesegyházi kincstár paramentumai [Die Paramente der Domschatzkammer Esztergom], Budapest: Stephaneum, 1933; Esztergom múemlékei. Múzeumok, kincstár, könyvtár [Denkmäler in Esztergom. Museen, Schatzkammer, Bibliothek], in Magyarország múemléki topográfiája [Denkmaltopographie Ungarns], Bd. 1.1, hrsg. von GEREVICH, Tibor, Budapest: o. V., 1948. 274, Abb. 290; CsÉFalvaY, Pál: Der Domschatz zu Esztergom, Budapest: Corvina, 1984. 26, Kat. 53a-b; Cséfalvay, Pál: Die Basilika, der Domschatz und der Burgberg zu Esztergom, Budapest: Helikon 1992. 58; CsÉFALVAY, Pál: A magyar kereszténység ezer éve [Tausend Jahre Christentum in Ungarn], Magyar Nemzeti Múzeum [Ungarisches Nationalmuseum] Budapest, Budapest: Magyar Katolikus Püspöki Konferencia, 2001. 320, Abb. 3.37.

${ }^{67}$ Es stellt sich die Frage, weshalb Christus im Gegensatz zu Maria ohne Hals und mit Liliennimbus abgebildet ist. Es scheint, dass Christus auf einer anderen Realitätsebene als Maria dargestellt wird, nämlich viel mehr als Bild. Er ist der vera icon nicht unähnlich, die nur das Gesicht Christi zeigt (vgl. Abb. 15). Die Anordnung beider Diptychonhälften wirkt aufgrund des nach rechts oben gehenden Blicks von Maria und ihrer insgesamt leichten Drehung nach rechts etwas unstimmig, so als müsste sie sich eigentlich links von Christus befinden.

${ }^{68}$ Lexikon der christlichen Ikonographie, hrsg. von KIRSCHBaUm, Engelbert, Bd. 1, Freiburg i. Br.: Herder, 1968. Sp. 183-187, hier Sp. 183 (Art. Arma Christi). Die zugehörige Bibelstelle lautet: „Und dann wird erscheinen das Zeichen des Menschensohns am Himmel. Und dann werden wehklagen alle Geschlechter auf Erden und werden sehen den Menschensohn kommen auf den Wolken des Himmels mit großer Kraft und Herrlichkeit. - Et tunc parebit signum Filii hominis in caelo et tunc plangent omnes tribus terrae et videbunt Filium hominis venientem in nubibus caeli cum virtute multa et maiestate", (Matth. 24,30).

${ }^{69}$ Zum Beispiel Ablassblatt mit Gregorsmesse. Niederlande, um 1460. Kolorierter Holzschnitt, 25,3×18,1 cm. Nürnberg, Germanisches Nationalmuseum, Inv.-Nr. H 13, Kapsel 6. In Spiegel der Seligkeit 2000 (vgl. Anm. 16), 286-387 (Kat. 220: Doosry, Yasmin). Obwohl hier die Gregorsmesse abgebildet ist, bezieht sich die siebenzeilige Bildunterschrift auf die Betrachtung „unseres Herrn Waffen“. Sie verspricht jedem, der vor dem Bild kniend drei Vaterunser und drei Ave Maria spricht und seine Sünden bereut, 14 Jahre Ablass, gewährt durch Papst Gregor, zwei weitere Päpste und 40 Bischöfe.

${ }^{70}$ Vgl. auch SuCKALE, Robert: Arma Christi, Städel-Jahrbuch 6. 1977. 177-208, hier 182

${ }^{71}$ BeRns, Jörg Jochen: Film vor dem Film. Bewegende und bewegliche Bilder als Mittel der Imaginationssteuerung in Mittelalter und Früher Neuzeit, Marburg: Jonas, 2000. 35-36.

72 LENTES 2002 (vgl. Anm. 15), 207.

73 SuCKALE 1977 (vgl. Anm. 70), 186

${ }^{74}$ SuCKale 1977 (vgl. Anm. 70), 187. 
${ }^{75}$ Reliquiar in Form eines Triptychons mit Engelpietà zwischen Maria und Johannes. Paris, um 1400-1410. Gold und Email, $12 \times 12,7 \mathrm{~cm}$ (geöffnet). Amsterdam, Rijksmuseum, Inv.-Nr. BK-17045.

${ }^{76}$ RimMELe 2010 (vgl. Anm. 65), 63.

${ }^{77}$ Rimmele 2010 (vgl. Anm. 65), 196.

78 Bei dem eingangs erwähnten Mirakelmann von Döbeln war das Lendentuch separat aus Stoff gearbeitet. Das Bedecken des entkleideten Christus durch den Schleier seiner Mutter Maria stellte in Passions- und Mysterienspielen eine wichtige Szene dar: TRIPPS 2009 (vgl. Anm. 10), 121-124. In der Gestaltung des Lendentuchs beim Brandenburger Schmerzensmann könnte eine Art Reminiszenz an solche Szenen vorliegen. Die kostbare Gestaltung entspricht der Vorstellung, dass es sich um den Schleier Mariens handelte.

79 Siehe dazu z.B. Jörg Haspel zu Bibrach: Vision des heiligen Bernhard. Süddeutschland, um 1440-1460. Kolorierter Einblattholzschnitt, 28,5×20,5 cm. Wien, Albertina, Graphische Sammlung, Inv.-Nr. DG1930/133; Abb. in Albertina Sammlungen Online: http://sammlungenonline.albertina.at/? query=Inventarnummer=[DG1930/133] \&showtype=record (26. Juni 2018).

80 Sog. Meister Francke: Schmerzensmann. Hamburg (?), erstes Viertel 15. Jh. Tempera auf Eichenholz, $42,5 \times 31,3 \mathrm{~cm}$. Leipzig, Museum der bildenden Künste, Inv.-Nr. 243. Im Rahmen dieses Aufsatzes kann keine Auswertung der Forschung zu diesem Künstler und seiner Werkstatt erfolgen. Verwiesen sei auf das aktuellste Werk, mit ausführlicher Auswertung der bisherigen Literatur: Meister Francke revisited. Auf den Spuren eines Hamburger Malers, hrsg. von NüRnBERGER, Ulrike - RÄSÄNEN, Elina AlbreCHT, Uwe, Petersberg: Michael Imhof, 2017.

${ }^{81}$ Dendrochronologisch kann die Entstehung der Tafel ab 1394 angenommen werden: CASTRO, Silvia: Kunsttechnologische Einblicke in die Arbeitsweise des Malers des Thomas-Retabels der Hamburgischen Englandfahrer, gen. Meister Francke, in NüRNBERGER-RÄSÄNEN-ALBRECHT 2017 (vgl. Anm. 80), 163-201, hier 165 (unter Verweis auf die Forschungen von Peter Klein).

82 Allgemein zum Bildtypus: Osten, Gert von der: Engelpietà, in Reallexikon zur Deutschen Kunstgeschichte, Bd. 5. 1960. Sp. 601-621. RDK Labor: http://www.rdklabor. de/w/?oldid=93200 (26. Juni 2018).

${ }^{83}$ Ich danke Rüdiger Beck, Chefrestaurator im Museum der bildenden Künste Leipzig, für diese Angaben.

${ }^{84}$ Eine sehr ähnliche Gestaltung mit etwas einfacher wirkenden vergoldeten Rosetten auf dunkelblauem Grund zeigt das so genannte Norfolk-Triptychon, das aber insgesamt ein breiteres Rahmenprofil besitzt. Norfolk-Triptychon. Bistum Liège (?), um 1410-1415. Tempera auf Holz, Mitteltafel $33 \times 32 \mathrm{~cm}$, Flügel $33 \times 13 \mathrm{~cm}$. Rotterdam, Museum Boymans-Van Beuningen, Inv.-Nr. 2466; Abb. in The art of devotion 1994 (vgl. Anm. 16), 119-120 und 121, Taf. 38. Für die Auskunft über den Rahmen danke ich Friso Lammertse, Kurator der Alten Meister im selben Museum. Eine Beschreibung des Werks und seines Rahmens mit Verweis auf den Leipziger Schmerzensmann findet sich bei PANOFSKY, Erwin: Early Netherlandish Painting, Bd. 1, Cambridge (Mass.): Harvard University Press, 1953. 92 mit Anm. 4.

${ }^{85}$ KRÖNIG, Wolfgang: Rheinische Vesperbilder aus Leder und ihr Umkreis, Wallraf-Richartz-Jahrbuch 24. 1962. 97-192, hier 146-156.
${ }^{86}$ KeLLER, Hildegard Elisabeth: Rosen-Metamorphosen, in Der Rosenkranz 2003 (vgl. Anm. 17). 49-69, hier 62-63; As-Vijvers, Anne Magreet W.: Weaving Mary's Chaplet. The Representation of the Rosary in Late Medieval Flemish Manuscript Illumination, in Weaving, Veiling, and Dressing. Textiles and their Metaphors in the Late Middle Ages, hrsg. von RuBY, Kathryn - BAERT, Barbara, Turnout: Brepols, 2007, 41-79, hier 43

${ }^{87}$ Oberrheinisch, um 1420-1430. Lindenholz, Reste einer Farbfassung, 43,6×40,1 cm. Berlin, Staatliche Museen, Skulpturensammlung und Museum für Byzantinische Kunst, Inv.-Nr. 8477; Abb. in Staatliche Museen zu Berlin Digital. Online-Datenbank der Sammlungen: http://www. smb-digital.de/eMuseumPlus?service=ExternalInterface $\& \mathrm{~m}$ odule $=$ collection $\&$ objectId $=863161 \&$ viewType $=$ detail $V i e w$ (28. Juni 2018).

88 Osten 1933 (vgl. Anm. 16), 2; Mersmann 1952 (vgl. Anm. 16), 14 und 20. In einem späteren Lexikoneintrag revidiert Mersmann jedoch diese Deutung: Mersmann, Wiltrud: Schmerzensmann, in LCI (vgl. Anm. 68), Bd. 3, Freiburg i. Br.: Herder, 1971. Sp. 87-95, hier Sp. 88. Sie nimmt dabei Bezug auf BerLiner, Rudolf: Bemerkungen zu einigen Darstellungen des Erlösers als Schmerzensmann, in Rudolf Berliner (1886-1967): The Freedom of Medieval Art und andere Studien zum christlichen Bild, hrsg. von SuCKALE, Robert, Berlin: Lukas, 2003. 192-212, hier 195. Der AngelusMissae-Deutung folgt: ScHLie, Heike: Bilder des Corpus Christi. Sakramentaler Realismus von Jan van Eyck bis Hieronymus Bosch, Berlin: Mann, 2002, 186-187.

89 SChrade 1930 (vgl. Anm. 13), 177.

${ }^{90}$ Zum Veronikabild siehe ausführlich: BENKER, Sigmund: Vera icon. 1200 Jahre Christusbilder zwischen Alpen und Donau. Ausstellungskatalog, Diözesanmuseum Freising, München: Schnell und Steiner, 1987; KuRYLUK, Ewa: Veronica and her Cloth. History, Symbolism and Structure of a True Image, Cambridge (Mass.): Blackwell, 1991.

${ }^{91}$ NüRNBERGER, Ulrike: Ein Maler in Hamburg, gen. Meister Francke. Christus als Schmerzensmann in Leipzig und Hamburg, in NÜRNBERGER-RÄSÄNEN-AlBRECHT 2017 (vgl. Anm. 80), 94-109, hier 99.

92 Ich danke Rüdiger Beck für diese Angaben; siehe auch Nürnberger 2017 (vgl. Anm. 91), 99.

93 Schmid, Viktor: Painted Piety. Panel Paintings for Personal Devotion in Tuscany 1250-1400, Florenz: Centro Di, 2005. 44.

${ }^{94}$ Meister von St. Laurenz: Notgottes. Westfalen/Köln, um 1415. Malerei auf Eichenholz, 23,2× 15,7 cm. Köln, Wallraf-Richartz-Museum und Fondation Corboud, Dep. 0363.

${ }^{95}$ Die Ausmessung hat Rüdiger Beck am 5. Oktober 2011 vorgenommen. Abweichend davon: NürnBERGER 2017 (vgl. Anm. 91), 98, die 0,2 cm misst.

${ }^{96}$ Die Bohrlöcher auf der Rück- und Oberseite des Schmerzensmannes sind jüngeren Datums und möglicherweise Spuren einer späteren Hängung nach erfolgter Trennung der Tafel aus einem größeren Zusammenhang.

97 So auch die Vermutung von NüRnBERGER 2017 (vgl. Anm. 91), 101.

${ }^{98}$ Böhmischer Meister: Diptychon mit Maria mit dem Kind und Christus als Schmerzensmann, um 1360. Holz, mit Leinwand überzogen, je $25 \times 18,5 \mathrm{~cm}$. Kunsthalle, Karlsruhe, Inv.-Nr. 2431 a/b; Abb. in CAmille 1996 (vgl. Anm. 61), 116/117, Abb. 81. 
${ }^{99}$ Dieser Bildtypus der Madonna mit dem Kind wurde in Byzanz als „Pelagonitissa“ bezeichnet.

${ }_{100}$ Madonna mit Kind und Schmerzensmann, um 1330. Tempera auf Holz, 35,2 ×25,9 cm (linker Flügel), 35,3×26 cm (rechter Flügel). Altenburg, Lindenau-Museum, Inv.-Nr. 47-48; Abb. bei SANDER, Jochen: Marien- und Christusbilder, in KultBild 2006 (vgl. Anm. 16), 177-212, hier 178179, Taf. 45-46.

${ }^{101}$ Kermer, Wolfgang: Studien zum Diptychon in der sakralen Malerei, Düsseldorf: Stehle, 1967. 4.

102 Sog. Meister Francke: Schmerzensmann. Mischtechnik auf Holz, 92,5×67 cm. Hamburg, um 1435. Hamburg, Kunsthalle, Inv.-Nr. 499.

${ }^{103}$ Camille, Michael: Seductions of the flesh. Meister Francke's female man of sorrows, in SCHREINER 2002 (vgl. Anm. 15). 243-269, hier 257-258. Camille beschreibt das Bild aufgrund seiner Größe als öffentliches Bild. NüRNBERGER 2017 (vgl. Anm. 91), 102 nimmt auf ältere Vorschläge Bezug, die das Werk an einem Kirchenpfeiler lokalisieren.

104 PANOFSKY 1927 (vgl. Anm. 16), 284 und 286-289; RidDERBOS, Bernhard: The Man of Sorrows. Pictorial images and metaphorical statements, in MACDONALD-RIDDERBOS 1998 (vgl. Anm. 16), 145-181, hier 174.

105 RingBom, Sixten: Icon to Narrative. The Rise of the Dramatic Close-Up in Fifteenth Century Devotional Painting, Åbo: Akademi, 1965. 48.

${ }^{106}$ Eine solche Beobachtung hat Stefan Weppelmann an dem bereits erwähnten Diptychon von Pietro Lorenzetti gemacht: Weppelmann, Stefan: Kollektives Ritual und persönliche Andacht. Kleinformate in der Tafelmalerei des Trecento, in KultBild 2006 (vgl. Anm. 16). 213-250, hier 232-233. Die Madonna überschneidet mit ihrem Gewand und ihrem Nimbus den äußeren Rahmen.

107 SCHMidt 2005 (vgl. Anm. 93), 158.

108 Camille, Michael: Mimetic Identification and Passion Devotion in the Later Middle Ages. A Double-Sided Panel by Meister Francke, in MACDONALD-Ridderbos 1998 (vgl. Anm. 16). 183-211, hier 192-194.

${ }^{109}$ Camille 1998 (vgl. Anm. 108), 192.

110 Camille 2002 (vgl. Anm. 103), 245.

111 TAMmEn, Silke: Blick und Wunde - Blick und Form. Zur Deutungsproblematik der Seitenwunde Christi in der spätmittelalterlichen Buchmalerei, in Bild und Körper im Mittelalter, hrsg. von MAREK, Kristin - PREISINGER, Raphaèle, Paderborn: Fink, 2006. 85-114, hier 88. Tammen bezieht sich hier vor allem auf Andachtsbücher, die aber eben auch ein kleines Format bieten.

112 Weppelmann 2006 (vgl. Anm. 106), 220 spricht von kleinformatigen Tafelbildern, ihre nahsichtige Betrachtungsweise lässt sich aber auch auf Kleinformate anderer Gattungen übertragen.

113 Hier lässt sich der von Christine Göttler für Nebenfiguren und Randszenen in niederländischen Bildern verwendete Begriff der figura passionis übertragen: GöTTLER, Christine: Figura passionis. Abraham und Isaak im Stundenbuch der Maria von Burgund. Affekt und religiöse Erinnerung in der frühniederländischen Malerei, in Isaaks Opferung (Gen 22) in den Konfessionen und Medien der Frühen Neuzeit, hrsg. von STEIGER, Johann Anselm - Heinen, Ulrich, Berlin: De Gruyter, 2006. 153-184. Die dem Schmerzensmann beigestellten Figuren dienen demnach als Vorbilder für die Erzeugung von Emotionen beim Betrachter.
${ }^{114}$ Rimmele 2009 (vgl. Anm. 50), 113.

115 SCHOLten 2011 (vgl. Anm. 19), 12.

116 Kammel, Frank Matthias: Imago pro domo. Private religiöse Bilder und ihre Benutzung im Spätmittelalter, in Spiegel der Seligkeit 2000 (vgl. Anm. 16). 10-33, hier 16; НАмm 2009 (vgl. Anm. 6), 21.

${ }^{117}$ Hamm 2009 (vgl. Anm. 6), 49.

118 Tatsächlich lässt sich bereits 1598 in dem von Johann Baptist Fickler erstellten Inventar der Münchner herzoglichen Kunstkammer eine Betnuss nachweisen, die mit anderen kleinformatigen Artificalia präsentiert wurde: Johann Baptist Fickler. Das Inventar der Münchner herzoglichen Kunstkammer von 1598. Transkription der Inventarschrift cgm 2133, hrsg. von Diemer, Peter, München: Verlag der Bayerischen A. d. W., 2004. 63.

119 Kammel 2000 (vgl. Anm. 116), 17. Kammel bezieht sich hier vor allem auf die städtische Gesellschaft, in der sich Patrizier und wohlhabende Kaufleute mit exklusiven Andachtsobjekten sozial abheben wollten.

120 WarnKe, Martin: Der Hofkünstler, Köln: DuMont, 1985. 11 und 286.

${ }^{121}$ Dies konnte auch für Reliquien gelten, wie Silke Tammen an einem böhmischen Dornenreliquiar vorführt: TAMMEN, Silke: Dorn und Schmerzensmann. Zum Verhältnis von Reliquie, Reliquiar und Bild in spätmittelalterlichen Christusreliquiaren, in Reliquiare im Mittelalter, hrsg. von Reudenbach, Bruno - Toussaint, Gia, Berlin: Akademie, 2005. 187-208, hier 193. Die Dornenkrone befand sich seit 1239 im Besitz der französischen Könige und sie verschenkten sie regelmäßig zur Bestätigung ihrer Verbundenheit mit anderen Höfen, unter anderem dem böhmischen.

122 Belting, Hans: Bild und Kult, München: Beck, 1990. 474. Als Beweis z.B. für eine fehlende Lesefunktion bei den fürstlichen Stundenbüchern nennt Belting ihre überreiche Ausstattung mit Bildschmuck. Ein eindrucksvolles Beispiel ist das Stundenbuch des Herzogs von Berry: Gebrüder Limburg und Jean Colombe: Les Très Riches Heures. Burgund, 1410-1416. Malerei auf Pergament, 30×21, $5 \mathrm{~cm}$. Chantilly, Musée Condé, Ms. 65. Dazu: König, Eberhard: Die Belles Heures des Duc de Berry, Darmstadt: Wissenschaftliche Buchgesellschaft 2004.

123 Pomian, Krzysztof: Der Ursprung des Museums. Vom Sammeln, Berlin: Wagenbach 1998. 33-34.

124 Belting 1990 (vgl. Anm. 122), 477 schreibt dazu: „Der Markt verändert in der Ära des Privatbildes die Bedingungen des religiösen Bildes."

125 Ein interessantes Beispiel hierfür stammt aus dem Simplicissimus: Er betrachtet die Stücke einer Kunstkammer und erklärt, vom Besitzer danach gefragt, dass ihm das Bild eines Ecce Homo am besten gefiele, worauf ihm der kunstsinnige Besitzer eine chinesische Karte entgegenhält, die er wegen ihrer Seltenheit dem religiösen Bild vorzieht: GRIMMELSHAUSEN, Hans Jakob Christoph von: Der abenteuerliche Simplicissimus und andere Schriften, Bd. 1, hrsg. von Keller, Adelbert, Stuttgart: Litterarischer Verein, 1854. I. 1. 24, 145.

126 Wetter 2011 (vgl. Anm. 19), 64-70.

127 Sog. Werkstatt des Adam Dircksz: Betnuss mit Geburt Christi (oben) und Anbetung der drei Magier (unten). Nordniederlande, 1500-1530. Buchsbaum geschnitzt, Dm. $3,5 \mathrm{~cm}$. Niederlande, Privatsammlung. Siehe SCHOLTEN 2017 (vgl. Anm. 18), 63 und Abb. 54.

${ }^{128}$ FALKENBURG 1999 (vgl. Anm. 58), 32. 
129 Berns 2000 (vgl. Anm. 71), 36.

130 Husemann, Simone: Pretiosen persönlicher Andacht, in Spiegel der Seligkeit 2000 (vgl. Anm. 16), 54-68.
131 Husemann 2000 (vgl. Anm. 130), 54.

132 Belting 1990 (vgl. Anm. 122), 472. 